University of Louisville

ThinkIR: The University of Louisville's Institutional Repository

Electronic Theses and Dissertations

$12-2021$

\title{
Preclinical development of epicertin, a novel biotherapeutic for the treatment of ulcerative colitis.
}

Micaela Ann Reeves

University of Louisville

Follow this and additional works at: https://ir.library.louisville.edu/etd

Part of the Medical Pharmacology Commons, and the Medical Toxicology Commons

\section{Recommended Citation}

Reeves, Micaela Ann, "Preclinical development of epicertin, a novel biotherapeutic for the treatment of ulcerative colitis." (2021). Electronic Theses and Dissertations. Paper 3615.

https://doi.org/10.18297/etd/3615

This Master's Thesis is brought to you for free and open access by ThinkIR: The University of Louisville's Institutional Repository. It has been accepted for inclusion in Electronic Theses and Dissertations by an authorized administrator of ThinkIR: The University of Louisville's Institutional Repository. This title appears here courtesy of the author, who has retained all other copyrights. For more information, please contact thinkir@louisville.edu. 
PRECLINICAL DEVELOPMENT OF EPICERTIN, A NOVEL BIOTHERAPEUTIC

FOR THE TREATMENT OF ULCERATIVE COLITIS

\author{
By \\ Micaela Ann Reeves \\ B.A., Hanover College, 2018

\begin{abstract}
A Thesis
Submitted to the Faculty of the in Partial Fulfillment of the Requirements for the Degree of

Master of Science

in Pharmacology and Toxicology

Department of Pharmacology and Toxicology

University of Louisville

Louisville, Kentucky
\end{abstract} \\ School of Medicine of the University of Louisville
}

May 2021 
Copyright 2020 by Micaela Ann Reeves

All rights reserved. 

PRECLINICAL DEVELOPMENT OF EPICERTIN, A NOVEL BIOTHERAPEUTIC FOR THE TREATMENT OF ULCERATIVE COLITIS

\author{
By \\ Micaela Ann Reeves \\ B.A., Hanover College, 2018 \\ A Thesis Approved on
}

April 6, 2021

by the following Thesis Committee:

Dr. Nobuyuki Matoba

Dr. Krystal Hamorsky

Dr. Kavitha Yaddanapudi

Dr. Gerald T. Dryden

Dr. Wenke Feng

Dr. Leah Siskind 


\section{DEDICATION}

This thesis is dedicated to my late grandmother Mrs. Dixie Lou Akers

whose lifetime dedication to teaching inspires me to constantly seek new educational opportunities. 


\section{ACKNOWLEDGMENTS}

I would like to thank my mentor, Dr. Nobuyuki Matoba, for trusting in my abilities at the beginning of my scientific journey. Without his support, patience, and faith in my ability to lead projects independently I would not be the scientist I have developed into today. More importantly, the lessons I have learned from him have shaped me into the confident, well-rounded individual I had hoped to become upon starting this program. I would like to thank my family for their constant support and investment into my educational journey: Evan Reeves, Molly Reeves, Tim and Denise Akers, Sally Akers, and Steven and Lindsay London. Finally, thank you to Zack Henderson for listening to my ramblings and being my emotional support during the toughest times. He showed me that the greatest moments in life truly do come at those most unexpected. 


\title{
ABSTRACT \\ PRECLINICAL DEVELOPMENT OF EPICERTIN, A NOVEL BIOTHERAPEUTIC FOR THE TREATMENT OF ULCERATIVE COLITIS
}

\author{
Micaela Ann Reeves
}

April 6, 2021

Epicertin (EPT) is a recombinant variant of the cholera toxin B subunit with a Cterminal KDEL endoplasmic retention motif. Previously, orally administered EPT demonstrated mucosal healing activity in acute and chronic dextran sulfate sodium colitis models, indicating its therapeutic potential for ulcerative colitis (UC) treatment. However, oral dosing with EPT requires neutralization of gastric acid prior to administration, hindering its facile application in the treatment of chronic diseases like UC. One solution to this issue is that EPT may also be administered intracolonically without losing efficacy. This work describes the determination of a target intracolonic dose of EPT for future first-in-human safety trials as well as the development of a prototype oral formulation of EPT that prevents stomach acid degradation for $\mathrm{pH}$ dependent release at the colon. 


\section{TABLE OF CONTENTS}

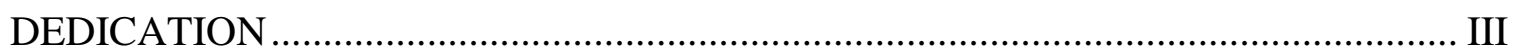

ACKNOWLEDGMENTS ............................................................................. IV

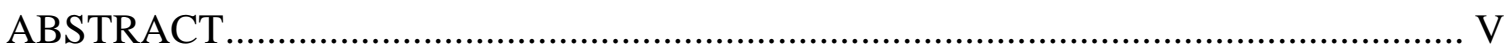

LIST OF FIGURES .....................................................................................

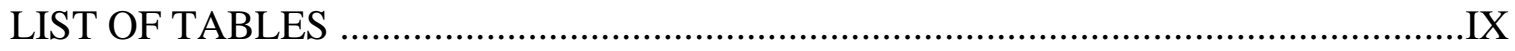

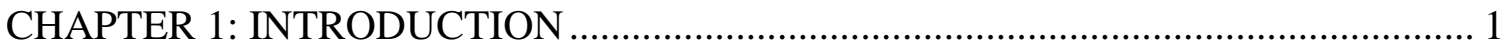

1.1. EPT facilitates mucosal healing: A novel therapeutic target for ulcerative

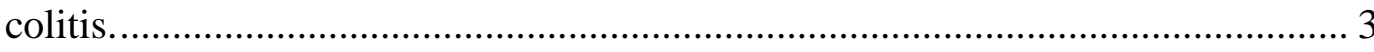

1.2. Current production process and formulation of EPT ............................... 10

1.3. Routes of administration with respect to ulcerative colitis........................ 11

1.4. Oral drug delivery options and dried formulations................................. 12

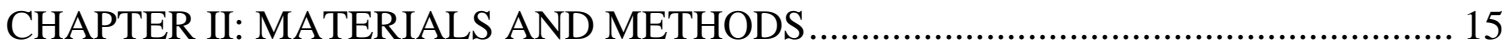

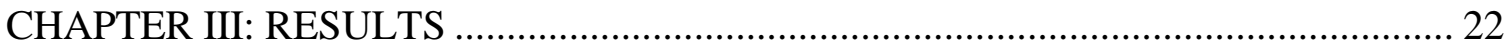

3.1. EPT at an intracolonic dose of $0.1 \mu \mathrm{M}$ is most effective at mitigating acute

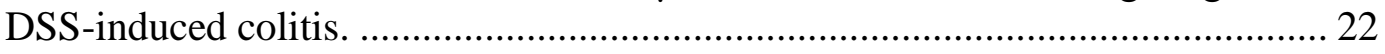

3.2. Pre-formulation analysis of a prototype oral formulation of EPT............... 25

3.3 Stability and disintegration testing of EPT capsules.................................. 26

3.4. Efficacy of EPT enteric-coated capsules in an acute colitis model. .............. 29

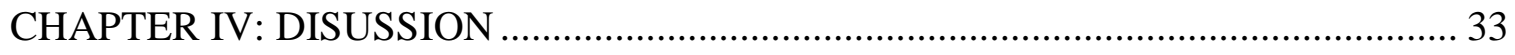

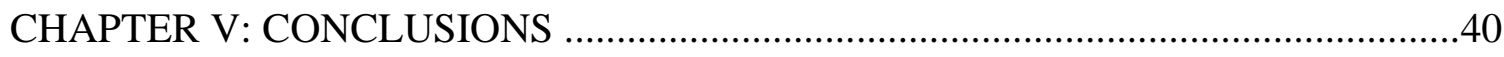


REFERENCES

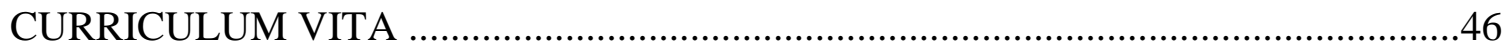




\section{LIST OF TABLES}

\section{TABLE}

TABLE 1 - Determination of optimal buffer excipient for EPT powder production........18

TABLE 2 - Stability of EPT powder in chosen buffer excipients................................25

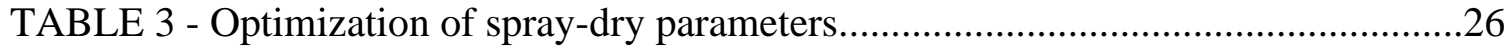




\section{LIST OF FIGURES}

\section{FIGURE}

FIGURE 1 - Dose level analysis of intracolonic administration of EPT.........................23

FIGURE 2 - Effects of intracolonic treatment with EPT on mice colon histological

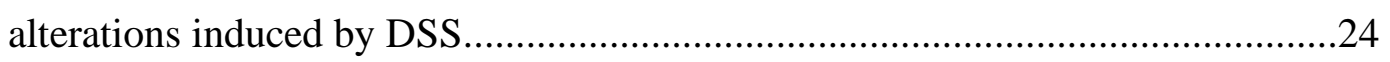

FIGURE 3 - Stability assessment of spray dried EPT ..............................................27

FIGURE 4 - Methodology to detect pentamer versus monomer EPT..........................28

FIGURE 5 - EPT released from enteric-coated capsules is $\mathrm{pH}$-dependent.....................29

FIGURE 6 - Enteric-coated EPT capsules mitigate acute DSS colitis in mice..................30

FIGURE 7 - Treatment with encapsulated EPT mitigates acute colitis in mice...............31 


\section{CHAPTER 1: INTRODUCTION}

The cholera toxin B subunit (CTB) is the homopentameric subunit of the cholera toxin. The cholera toxin is comprised of this nontoxic B subunit and the toxic catalytic A subunit [1-3]. CTB binds to GM1 ganglioside to mediate entry of the whole toxin into the cell via retrograde transport to the endoplasmic reticulum (ER) [4]. CTB exhibits strong immunomodulatory effects under normal and various immunopathological conditions [5, 6]. For example, a WHO pre-qualified oral cholera vaccine, Dukoral®, contains heatkilled whole cell Vibrio cholerae and recombinant CTB [5, 7]. However, CTB can induce potent mucosal and systemic antibody responses in humans on its own [8-10]. A plantmade recombinant CTB variant, epicertin (EPT), featuring a C-terminal hexapeptide ER retention motif -KDEL exhibits mucosal healing activity unlike CTB. A unique feature of EPT is its established ability to be efficiently manufactured in a Nicotiana benthamiana transient production system [11]. EPT was initially engineered as a potential solution to the cost and scale challenges in CTB biomanufacturing to aid in mass vaccination against cholera outbreaks $[12,13]$. However, EPT may have a separate role as a potential novel therapeutic for ulcerative colitis [14].

Ulcerative colitis (UC) is a major form of inflammatory bowel disease (IBD), characterized by chronic and relapsing inflammation of the innermost layer of the colon and rectal mucosa $[15,16]$. Its etiology remains poorly understood and the onset is associated with a complicated interplay of genetic and environmental factors as well as gut 
microbiota [17]. The disease often manifests as a multitude of symptoms: bloody diarrhea, rectal bleeding, fatigue, and weight loss. However, symptom presentation often varies among patients and may change over time with increasing severity of disease [16]. The Crohn's and Colitis Foundation estimates that approximately 1.6 million Americans suffer from IBD with a total US annual financial burden between $\$ 14.6$ billion and $\$ 31.6$ billion. UC accounts for 907,000 of these cases with an annual incidence of 12.2 per 100,000 people [16]. Current FDA-approved UC drugs aim to treat existing symptoms, maintain remission, and improve quality of life. Despite multiple treatment options available to UC patients, none of them can cure the disease, and up to a third of those with 30+ years of the disease will require surgical removal of the colon and rectum [16].

There are several classes of drugs used to treat UC [16]. Typically, UC treatment follows a step-up approach in which drug class utilization is dependent upon disease severity and response to prior therapies. The final step of this treatment strategy is surgical intervention $[18,19]$. Treatment with 5-aminosalicylates (ASAs) has long been the mainstay first-line therapy for mild-to-moderate UC [16, 20]. This inflammationblunting class of therapeutics are preferred for early-stage UC because of their generally innocuous side effect profiles, although moderate UC is often unresponsive to these agents [19]. The mild side effect profile is counteracted by the ability of patients to develop tolerance during remission maintenance and require new treatment strategies. Failure to achieve or maintain remission with 5-ASAs is typically followed by treatment with corticosteroids and steroid-sparing immunomodulators. An estimated two-thirds of patients receiving short-term steroid treatment for moderate to severe UC achieve remission. However, the risk of serious adverse effects limit long-term use of these 
agents [18-21]. Biologics (e.g. anti-TNF $\alpha$ and anti-integrin monoclonal antibodies) have traditionally been the final agents utilized to treat severe UC prior to surgical resection of the colon and rectum, although recent literature suggests the benefit of using biologics in earlier stages [22]. These drugs are effective in remission induction and maintenance in patients following previous treatment failures but are partnered with the serious side effects including severe infection and increased cancer risk [20, 21]. Of particular note, fewer than half of patients treated with biologics are able to achieve mucosal healing, an endoscopic marker found to be highly predictive of sustained clinical remission, better quality of life, and decreased risk for colitis-associated colorectal cancer [23, 24].

Further, biologics are typically more expensive than other therapeutic agents [25]. Therefore, there is a current unmet need in UC therapy: agents that can directly restore the damaged epithelial barrier and facilitate mucosal healing without suppressing immune function such as EPT. In this chapter, I will summarize previous studies describing the mucosal healing activity of EPT, discuss the current EPT formulations under investigation and limitations as well as describe other potential formulation options.

\subsection{EPT facilitates mucosal healing: A novel therapeutic target for ulcerative colitis.}

Although originally designed to aid mass vaccination efforts against cholera outbreaks, we also assessed the immunomodulatory effects of EPT. Two weeks after two oral $30 \mu \mathrm{g}$ administrations of EPT, immune cell population analysis from the small intestine, colon, Peyer's patches, and spleen revealed that subsets of innate immune cell populations in the lamina propria of the colon were significantly increased in EPT-treated 
mice compared to control (M1 and M2 macrophages confirmed by immunohistochemistry, natural killer [NK] cells). $\mathrm{T}$ helper $(\mathrm{Th}) 2$, regulatory $\mathrm{T}$ (Treg) and Th17 cells were also increased following administration of EPT. Gene expression analysis further supported that EPT has a more targeted impact on the colon as 871 genes were significantly altered in the colon $(\mathrm{p}<0.01)$ while 184 genes were significantly altered in the small intestine in mice treated with EPT compared to vehicle control. Oral administration of EPT was shown to induce TgfbI, TgfbII receptor and Smad regulation, all of which are genes involved in transforming growth factor (TGF) $\beta$-associated pathways and epithelial wound healing [26]. For this reason, epithelial restitution potential of EPT was assessed using a human colon epithelial cell (Caco2) scratch assay. EPT significantly enhanced epithelial cell migration similarly to the TGF $\beta 1$ control compared to the vehicle control phosphate buffered saline (PBS) at 24 and $48 \mathrm{~h}$ post scraping the cell layer. Cell culture supernatant analyzed at $48 \mathrm{~h}$ showed that epicertin and TGF $\beta 1$ had similar inflammation and wound healing-related profiles relative to cytokines like epidermal growth factor (EGF), granulocyte colony-stimulating factor (GCSF), granulocyte-macrophage (GM)-CSF, interferon (IFN)- $\gamma$, interleukin (IL)-10, IL-6, and tumor necrosis factor (TNF) $\alpha$. This effect translated to an in vivo model of acute colitis induced by dextran sulfate sodium (DSS). EPT treatment significantly blunted weight loss induced by DSS and hematoxylin and eosin (H\&E)-stained distal colon tissue at 6 days post-DSS exposure reveled that EPT administration prevented crypt loss and ulceration compared to vehicle control. However, the numbers of infiltrating macrophages into the colon mucosa were similar between EPT and vehicle groups. Another in vivo study was performed to assess the immediate impact of EPT treatment on 
acute DSS-induced colitis. Mice were orally administered $30 \mu \mathrm{g}$ EPT or PBS twice before DSS exposure. A reference group of mice dosed daily with $100 \mu \mathrm{g}$ mesalazine during DSS exposure was also included. EPT- and mesalazine-treated mice similarly reduced mucosal damage as characterized by shorted yet visible basal crypts, mild inflammatory infiltrates, and epithelial cell surface retention. Gene expression and cytokine analysis from the distal colon showed that EPT treatment blunted escalation of inflammatory markers including IL-1 $\beta$, IL-6, and IFN- $\gamma$ among others. In an azoxymethane (AOM)/DSS mouse model of chronic colitis and colon cancer, biweekly EPT administration $(3 \mu \mathrm{g})$ significantly decreased disease activity index (DAI) scores following the first dose and more dramatically during the third DSS exposure period. This is a standard scoring system assessing the overall severity of colitis, which takes an average of scores from three categories: body weight, stool consistency, and blood in stool [27]. Tumorigenesis was also significantly reduced in both dose groups treated with EPT [14]. Taken together, these results highlight the potential role of EPT in UC therapy as a mucosal healing agent that specifically targets the colon.

Mucosal healing is a major treatment goal for UC patients [23, 24, 28, 29]. It is a complex and dynamic process involving multiple cell types including epithelial, stromal, and immune cells [28]. Epithelial repair plays a crucial role in mucosal healing by rebuilding the intestinal barrier to inhibit inflammation caused by entry of bacteria into the mucosa. Since inflammation in UC is limited to the innermost layer of the colon and rectal mucosa, epithelial repair may be key to effectively achieving mucosal healing in this subset of IBD patients [16, 23]. Currently there is no UC drug approved by FDA that 
specifically aims at recovering the colon epithelial barrier integrity. Thus, an epithelial repair agent, such as EPT, may fill a current treatment gap for UC.

We continued to investigate the mechanism of EPT-induced mucosal healing via epithelial repair, specifically the importance of its ER retention motif [30]. To test the ER retention activity of EPT, Caco2 cells were treated with EPT or CTB for $24 \mathrm{~h}$ and cell lysates were monitored for CTB retention for $24 \mathrm{~h}$. While CTB showed decreasing levels of retention with only marginal amounts detected at $24 \mathrm{~h}$, EPT was continuously detected in cell lysates over $24 \mathrm{~h}$. These results were corroborated with confocal microscopy in which EPT was depicted at much higher amounts inside Caco2 cells at 6 and $24 \mathrm{~h}$ compared to CTB. Coimmunoprecipitation results also indicated that EPT displayed clear binding to KDEL receptors that was not observed with CTB. These data indicate that EPT has prolonged residence in Caco2 cells due to its KDEL receptor interaction.

In Caco2 cells treated with EPT, CTB, a non-GM1 binding mutant of EPT (G33D EPT) or PBS, it was demonstrated that all 3 sensors of the unfolded protein response (UPR) pathways were upregulated at gene expression and protein levels only in EPTtreated cells [30]. The UPR is a system in which the ER can activate various intracellular signaling pathways to alleviate the accumulation of aberrant proteins. However, this response can also be triggered by adventitious proteins invading the ER, such as CTB $[31,32]$. One branch of the UPR, the inositol-requiring enzyme 1 (IRE1)- X-box binding protein 1 (XBP1) pathway has been linked to wound healing and mitigation of DSS colitis [33-35]. Some of the markers of the UPR analyzed were activating transcription 
factor 6 (ATF6), PKR-like ER kinase (PERK), IRE1, and immunoglobulin heavy chainbinding protein (BiP). Consistent with the Caco2 study, mouse primary colon epithelial cells treated with EPT for $24 \mathrm{~h}$ also significantly increased levels of IRE1 $\alpha$, PERK, and BiP compared to CTB and PBS-treated groups. A further coimmunoprecipitation assay indicated that Caco2 cells incubated with CTB or EPT for $1 \mathrm{~h}$ both were shown to interact with the ER chaperone, BiP, however, only EPT was shown to interact with BiP after $24 \mathrm{~h}$. To test the impact of the UPR on EPT's wound healing activity, a Caco2 scratch assay was performed in which cells were treated with EPT in the presence or absence of $4 \mu 8 \mathrm{C}$, a chemical inhibitor of the IRE1-XBP1 arm of the UPR. The UPR inhibitor was sufficient to completely block the wound closure activity of EPT, indicating that EPT exhibits wound healing activity via the IRE1-XBP1 signaling pathway [30].

Since EPT was demonstrated to activate an UPR in primary mouse colon epithelial cells, it was hypothesized that this enhanced epithelial repair was mediated by the IRE1 arm of the UPR. Most interestingly, these findings were also evaluated in human colon tissues ex vivo [30]. A sigmoid colon tissue of a UC patient who underwent total colectomy was sectioned into 9 pieces and cultures with EPT, CTB, or PBS ( $n=3)$ for $24 \mathrm{~h}$. Following incubation, UPR, TGF- $\beta$, and wound healing gene expression was analyzed. Consistent with Caco2 cell results, EPT-treated tissue showed a significant upregulation in the IRE1 gene (ERN1), PERK gene (EIF2AK3), and TGF-B1 with no significant difference observed between PBS- and CTB-treated tissues. Histopathological analysis showed the EPT-treated tissues also had early-stage crypt formations with low mucosal neutrophil infiltration, both of which were not seen in the PBS- or CTB-treated 
tissues. Altogether, the results of this study indicate that EPT has unique colon mucosal wound healing effects related to its ER retention and subsequent activation of the UPR [30].

In another study we evaluated the efficacy of EPT in the treatment of chronic colitis as well as addressed consequences of immunogenicity [36]. A chronic DSS colitis experiment in which mice were exposed to three cycles of 7-day DSS in drinking water followed by 14-day normal drinking water was performed (total in-life study period of 63 days). Mice were treated orally with $3 \mu \mathrm{g}$ EPT or PBS once weekly starting on day 7 , with $3 \mu \mathrm{g}$ EPT or PBS once weekly starting on day 35, or with $3 \mu \mathrm{g}$ EPT or PBS every 3 days starting at day 35 (6 dosing groups total). All EPT-treated groups showed immediate reduction in DAI scores. Mice receiving weekly EPT treatment starting from day 7 and every-3-day treatment from day 35 appeared to have improved barrier function compared to PBS-treated groups as indicated by serum FITC-dextran measurements at the conclusion of the study on day 63. No EPT treatment groups demonstrated an elevation of analyzed pro-inflammatory cytokines (IL- $1 \beta$, TNF $\alpha$, GM-CSF, and IFN- $\gamma$ ). Once weekly treatment with EPT starting at day 7 significantly decreased GM-CSF and IL-1 $\beta$ levels compared to PBS, and once weekly treatment with EPT starting at day 35 significantly decreased GM-CSF and IFN $\gamma$ levels compared to PBS. Histopathological examination corroborated the DAI, FITC-dextran, and cytokine analyses. Mice dosed with EPT once weekly starting from day 7 or every-3-day starting from day 35 demonstrated similar recovery and exhibited less crypt branching, crypt distortion, and expansion of the lamina propria than weekly dosing starting at day 35 . These results 
taken together indicate that once weekly or every-3-day EPT dosing can effectively mitigate chronic colitis and that the efficacy is maintained over a long period, raising an interesting question about the consequences of an immune response to the protein, which is derived from the mucosal immunostimulatory protein CTB.

To probe the potential impacts of anti-drug antibodies, an acute DSS study was performed in which three groups of C57B1/6 mice were administered either two oral doses of $30 \mu \mathrm{g}$ EPT prior to DSS exposure, dosed only one therapeutic dose of $3 \mu \mathrm{g}$ EPT on the final day of 7-day DSS exposure, or received both two oral doses of $30 \mu \mathrm{g}$ EPT prior to DSS exposure and one therapeutic dose of $3 \mu \mathrm{g}$ EPT on the final day of DSS exposure. Anti-EPT IgA titers were assessed on days 7 and 14 to determine if the immunogenicity of EPT impacts its efficacy. All EPT-treated groups showed a significantly more rapid body weight recovery after DSS cessation and all EPT groups showed similar DAI scores that were significantly lower than the PBS-treated mice. Both groups in which mice were dosed prior to DSS exposure had similar and high levels of anti-EPT $\operatorname{IgA}$ antibodies at days 7 and 14, indicating that anti-drug antibodies were present when EPT was administered therapeutically. Under the same experimental condition in $\mathrm{C} 3 \mathrm{H} / \mathrm{HeJ}$ mice, which are poor responders to $\mathrm{CTB}$ immunization, all EPT epicertin dose regimens were efficacious against DSS colitis compared to PBS-treated mice in terms of body weight recovery, colon length and DAI scores. Unlike the C57BL/6 mice, however, these mice had little or no anti-CTB IgA response to pre-dosing with EPT, indicating that EPT's therapeutic effects are unlikely dependent on IgA induction in the intestine. These results demonstrate that the immunogenicity of EPT 
dosing does not seem to impede its mucosal healing efficacy, further supporting the potential role of this molecule as a novel therapeutic for UC [36].

\subsection{Current production process and formulation of EPT}

The EPT production process has continuously been optimized over the last several years $[11-13,37]$. This variant of CTB is transiently overexpressed in a species of tobacco, Nicotiana benthamiana. Utilization of the GENEWARE® tobacco mosaic virus vector, we are able to purify approximately $400 \mathrm{mg}$ of EPT per $\mathrm{kg}$ of leaf tissue [37]. EPT is expressed using the GENEWARE® tobacco mosaic virus vector and inoculated into 21-day old $N$. benthamiana. Eleven days post-infection leaf tissues are harvested and EPT is extracted using a commercial blender and a 1:2 ratio of leaf tissue to extraction buffer. Following filtration and centrifugation steps, the supernatant is heated at $50^{\circ} \mathrm{C}$ for $45 \mathrm{~min}$ and undergoes further centrifugation to precipitate starches and host proteins. The $\mathrm{pH}$ of the resulting supernatant is adjusted from $\mathrm{pH} 5.0$ to 8.0 to precipitate the one more round of host proteins prior to purification. The EPT-containing supernatant is first purified by immobilized metal affinity chromatography (IMAC) using a metal affinity resin charged with $\mathrm{CoCl}_{2}$. This purification method utilizes CTB's ability to bind to divalent metal cations through internal histidine residues [38]. A second chromatography step using a ceramic hydroxyapatite resin with a gradient phosphate buffer elution step is used to isolate fully intact EPT from EPT species with truncations of the C-terminal -KDEL motif. By

this two-step chromatography method we are able to achieve approximately $95 \%$ purity of 
fully intact EPT [11]. The resulting drug product is a solution of EPT in PBS (pH 7.4) that is stored at $4^{\circ} \mathrm{C}$.

EPT may be administered to the colon topically or by oral gavage to alleviate DSSinduced colitis in mice [30]. Although oral medications are generally preferred by patients and increase patient adherence to treatment regimens $[17,39,40]$, oral administration of EPT solution requires neutralization of stomach acid to prevent degradation of the protein. This is similar to the WHO prequalified oral cholera vaccine, Dukoral®, which is administered in a solution following stomach neutralization with a sodium bicarbonate solution. Considering potential long-term treatment necessary for the management of UC [41], this neutralization step could be disadvantageous as it would likely lower patient adherence and ease of administration. Intracolonic administration is another option for EPT, as many UC drugs are enemas. However, enema formulations have their own advantages as well as limitations.

\subsection{Routes of administration with respect to ulcerative colitis.}

Deciding on a route of administration for a drug is not necessarily an easy choice when presented with multiple formulation possibilities. For EPT, several factors must be taken into consideration when deciding whether to move forward with an enema or oral formulation. An enema formulation has the benefit of direct topical application to the target site as well as lower potential for systemic off-target effects [17]. This would decrease the number of safety concerns that would need to be addressed during preclinical and clinical investigations. Intracolonic administration allows for rapid 
absorption of the drug and ensures delivery of optimal dosage as it by-passes first-pass metabolism [17]. Enema formulations can be especially beneficial to treat UC affecting the rectum and most distal sections of the colon [17]. However, enema formulations run the risk of decreasing patient adherence and are not as easily administered, two important factors to consider when developing drugs to treat chronic diseases like UC [41].

Oral medications are generally preferred by patients, which increases the likelihood that patients will adhere to treatment regimens $[17,39,40]$. They are easier for patients to self-administer and can be formulated with delivery systems to extend release, prevent stomach acid degradation, and allow for release of capsule contents at a specific $\mathrm{pH}[17,40]$. These benefits are countered with the need for higher doses to compensate for drug loss after first-pass metabolism and potential absorption throughout the GI tract prior to delivery at the target site [17]. Higher doses correspond to increased production costs per dose and ultimately higher costs for the patient. Further, development and production systems required to manufacture a drug with a specialized coating or delivery system can slow research efforts and become costly. With respect to EPT, an enema formulation is suitable for early safety and efficacy studies in humans, however, an improved solid oral formulation allowing for release at the distal colon would be optimal due to the need for adherence in the treatment of chronic diseases like UC.

\subsection{Oral drug delivery options and dried formulations.}

Biotherapeutics are often limited in their use as orally administered agents in UC due to degradation in the gastrointestinal tract, large molecular size, and poor permeation 
[42]. Therefore, the formulation of the drug product must be optimized to circumvent these issues. There are a variety of oral formulations currently used and more under investigation for the manufacturing of biotherapeutics. The formulation strategy employed depends on the properties of the drug itself. For example, poorly soluble drugs can be delivered by reducing particle size or adding surfactants to the drug substance [43]. Nanoparticle drug delivery systems are often used to protect a drug from the harsh environment of the gastrointestinal tract [44]. Another drug delivery system commonly used is an enteric polymer coating allowing for site-specific delivery based on $\mathrm{pH}$. These coatings are designed to remain stable and intact through the gastrointestinal tract and degrade once exposed to a specific $\mathrm{pH}$. This would be beneficial to prevent degradation of EPT in the gastric acid. Other coatings are microflora-triggered and are biodegraded by bacterial flora in the colon [43]. Drugs that utilize these coatings are often tablets or capsules filled with lyophilized or spray-dried drug substances.

There are two main dehydration processes in the world of pharmaceutical and biopharmaceutical development: spray drying and freeze drying (lyophilization) [45]. The primary drying method in industrial settings, lyophilization, is a two-step process in which ice is sublimated from frozen drug product followed by desorption of remaining water at low pressure and higher temperature to form a dried cake [46]. If a fine powder is required, another process must be added to break up the final cake [47]. The addition of this secondary step removes a certain amount of control from the manufacturers, reduces efficiency and increases production time $[47,48]$. Spray drying technology was originally improved to aid formulation development of small molecule drugs but has gained 
popularity in the world of biopharmaceuticals in recent decades. In contrast to lyophilization, spray drying is a one-step process in which the protein solution is atomized into a hot air-drying chamber and resulting particles settle in a product collector [48-50]. Although biopharmaceutical spray drying has its limitations on an industrial scale, it offers the following advantages to lyophilization: consistent powder quality, increased production control necessary to follow current Good Manufacturing Practice (cGMP) guidelines, significant energy cost savings, a wide range of dryer designs for specific applications, and ability to dry heat-sensitive and heat-resistant inputs [45]. For this reason, in addition to continuing to evaluate safety and efficacy of an intracolonic formulation of EPT, we began to develop an optimal oral formulation: a spray-dried capsule with an enteric polymer coating allowing for $\mathrm{pH}$-dependent release at the colon. The results herein describe a dose analysis study to determine an optimal dose level for intracolonically delivered EPT, as well as a prototype production process for a spraydried form of EPT and its efficacy as evaluated in an acute DSS colitis mouse model. 


\section{CHAPTER II: MATERIALS AND METHODS}

EPT production. EPT was produced in Nicotiana benthamiana using a transient overexpression system and purified to $>95 \%$ homogeneity with an endotoxin level of $<3$ endotoxin units per $\mathrm{mg}$ as described previously $[11,12,37]$. EPT was ultrafiltrated/diafiltrated into various buffers (Table 1) using 30,000 MWCO centrifugal devices. PBS with $100 \mathrm{mM}$ mannitol was found to be the optimal buffer for spray drying of EPT. EPT at $1 \mathrm{mg} / \mathrm{mL}$ in PBS with $100 \mathrm{mM}$ mannitol excipient (pH 7.2) was dehydrated using a Büchi B-290 mini spray drier with an inlet temperature of $125^{\circ} \mathrm{C}$ and an outlet temperature maintained between 65 and $67^{\circ} \mathrm{C}$. The Q-Flow was $35 \mathrm{~mm}$, aspirator was $90 \%$ and pump 20\%. EPT powder was stored in conical tubes wrapped in parafilm under desiccation at room temperature $\left(20-25^{\circ} \mathrm{C}\right)$ until use. Standard EPT used for the GM1/KDEL ELISA and SEC-HPLC was produced in Nicotiana benthamiana using a transient overexpression system and purified to $>95 \%$ homogeneity with an endotoxin level of $<3$ endotoxin units per $\mathrm{mg}$ as described previously $[11,12,37]$

\section{Acute DSS colitis model and EPT treatment for intracolonic dose level determination} study. Groups of 10 female C57BL/6 mice, randomly assigned, were used. 3\% DSS (M.W. 36,000 - 50,000; M.P. Biomedicals, Santa Ana, CA) was administered in drinking water ad 
libitum for 7 days. ${ }^{1}$ Body weights were monitored daily from the start of DSS exposure to sacrifice on day 12. On the last day of DSS exposure, animals were intracolonically administered $100 \mu \mathrm{L}$ of PBS, $0.01 \mu \mathrm{M}$ EPT, $0.1 \mu \mathrm{M}$ EPT, or $1 \mu \mathrm{M}$ EPT (corresponding to $0.0614 \mathrm{mg}, 0.614 \mathrm{mg}$, or $6.14 \mathrm{mg}$ EPT per animal). Animals recovered with normal drinking water for 5 days. Disease activity index (DAI) scores, consisting of body weight loss, fecal consistency and occult blood tests, were recorded following sacrifice and performed as previously described [51]. Distal colon tissues were fixed in neutral buffered formalin and stained with hematoxalin and eosin (H\&E). Histopathological scores, a combination score comprised of crypt architecture, inflammatory infiltrate, muscle thickening and goblet cell presences scores, were determined as previously described [52, 53]. Each category was ranked on a scale from 0 to 3 and summed to obtain a single histopathological damage score for each tissue.

EPT powder characterization. To measure residual moisture, a $5.9 \mathrm{mg}$ portion of dried powder was incubated at $70^{\circ} \mathrm{C}$ for $16 \mathrm{~h}$. Moisture content was calculated by weighing the difference before and after heating. To determine solubility, dried powder was weighed and a calculated volume of milli Q water was added to reconstitute EPT powder to $1 \mathrm{mg} / \mathrm{ml}$. The concentration of the reconstituted solution was measured by Nanodrop (Thermo Fisher Scientific) using an extinction coefficient at $A_{280}$ of 0.7857 . The percent solubility was calculated based on the difference in $1 \mathrm{mg} / \mathrm{mL}$ vs the determined nanodrop concentration.

${ }^{1}$ Eight-week-old C57BL/6J, female mice were obtained from Jackson Laboratories (Bar Harbor, ME). The University of Louisville's Institutional Animal Care and Use Committee approved all animal studies conducted in this thesis. 
Percent monomer was determined by size-exclusion high performance liquid chromatography (SEC-HPLC). SEC-HPLC was run as previously described [17]. Briefly, reconstituted EPT at $1 \mathrm{mg} / \mathrm{mL}$ was applied to a Tosoh TSKgel SuperSW3000 column using $100 \mathrm{mM}$ sodium phosphate, $\mathrm{pH}$ 7.2, $150 \mathrm{mM}$ sodium chloride running buffer. EPT standard (a bulk solution prepared in PBS before spray drying) was used as a control.

GM1-capture KDEL-detection (GM1/KDEL)-ELISA. The assay was done as described in Morris et al. [11]. Plates were coated with $100 \mu \mathrm{L}$ per well of $2 \mu \mathrm{g} / \mathrm{mL}$ GM1 ganglioside (Sigma Aldrich; St. Louis, MO) diluted in a coating solution consisting of $3 \mathrm{mM}$ sodium azide, $15 \mathrm{mM}$ sodium carbonate, $35 \mathrm{mM}$ sodium bicarbonate, $\mathrm{pH}$ 9.6. After overnight incubation $(16$ to $18 \mathrm{~h})$ at $4^{\circ} \mathrm{C}$, plates were washed three times with PBST $(0.05 \%$ Tween 20 in $1 \mathrm{X}$ PBS) and blocked with a blocking solution (5\% non-fat dry milk, 0.05\% Tween 20 in 1X PBS) for $1 \mathrm{~h}$ at room temperature, then washed with PBST thrice. Three-fold serially diluted, duplicate samples $(100 \mu \mathrm{L} /$ well $)$ were added to plates in 1\% PBSTM (1\% dry milk, $0.05 \%$ Tween 20 in $1 \mathrm{X}$ PBS). Samples were incubated on plates for $1 \mathrm{~h}$ at $37^{\circ} \mathrm{C}$. Plates were washed and mouse anti-KDEL monoclonal antibody (Enzo Life Sciences; Farmingdale, NY) diluted 1:1,000 in 1\% PBSTM $(100 \mu \mathrm{L} /$ well $)$ was added; plates were then incubated at $37^{\circ} \mathrm{C}$ for $1 \mathrm{~h}$. Plates were washed and goat anti-mouse IgG-HRP (Southern Biotech; Birmingham, AL) diluted 1:5,000 in 1\% PBSTM was added, followed by incubation at $37^{\circ} \mathrm{C}$ for $1 \mathrm{~h}$. Plates were washed a final time and developed with 3,3',5,5'-tetramethylbenzidine substrate (TMB). The reaction was stopped with $2 \mathrm{~N}$ sulfuric acid and the absorbance at $450 \mathrm{~nm}$ was immediately measured with a BioTek plate reader. 
Table 1.

Determination of optimal buffer excipient for EPT powder production.

\begin{tabular}{|c|c|c|c|}
\hline Buffer & \% Monomer & \% Moisture & \% Solubility \\
\hline PBS & 4.9 & 2.9 & 106 \\
\hline PBS, 20 mM Mannitol & 4.5 & 10.3 & 94 \\
\hline PBS, 100 mM Mannitol & 3.1 & 0 & 97 \\
\hline PBS, 150 mM Mannitol & 9.1 & 7.5 & 99 \\
\hline PBS, 250 mM Mannitol & 6.4 & 4.1 & 87 \\
\hline 30 mM Phosphate, $\mathrm{pH} 7$ & 3.2 & 31.5 & 67 \\
\hline 30 mM Phosphate, 20 mM Mannitol, pH 7 & 1.1 & 14.7 & 81 \\
\hline 30 mM Phosphate, 100 mM Mannitol, pH 7 & 5.8 & 2.3 & 97 \\
\hline 30 mM Phosphate, 150 mM Mannitol, pH 7 & 5.8 & 3.9 & 96 \\
\hline $30 \mathrm{mM}$ Phosphate, $250 \mathrm{mM}$ Mannitol, pH 7 & 6.7 & 5.4 & 91 \\
\hline $30 \mathrm{mM}$ Phosphate, $\mathrm{pH} 7.5$ & 6.1 & 20 & 79 \\
\hline $30 \mathrm{mM}$ Phosphate, $20 \mathrm{mM}$ Mannitol, $\mathrm{pH} 7.5$ & 2.4 & 21.3 & 82 \\
\hline 30 mM Phosphate, 100 mM Mannitol, pH 7.5 & 5.2 & 1 & 88 \\
\hline $30 \mathrm{mM}$ Phosphate, $150 \mathrm{mM}$ Mannitol, $\mathrm{pH} 7.5$ & 7.0 & 2.1 & 92 \\
\hline 30 mM Phosphate, $250 \mathrm{mM}$ Mannitol, $\mathrm{pH} 7.5$ & 7.3 & 3.1 & 64 \\
\hline 88 mM Phosphate, 20 mM Mannitol, pH 7 & 2.1 & 18.4 & 96 \\
\hline TARGET & $<5 \%$ & $<10 \%$ & $100+-10$ \\
\hline
\end{tabular}

EPT capsule package and preparation. Torpac size $M$ gelatin capsules were packed with $3 \mathrm{mg}$ dried EPT product per capsule (corresponding to $5 \mu \mathrm{g}$ of EPT) using the ProFunnel capsule filling system (Torpac; Fairfield, NJ). Capsule cap and body joints were painted with 4\% Eudragit L100 anionic polymer coating solution and allowed to dry for $20 \mathrm{~min}$. Capsules were loaded into a size $\mathrm{M}$ capsule holder and dipped just past the cap and body joints into 4\% Eudragit L100 coating solution and allowed to dry for $25 \mathrm{~min}$. Capsules were flipped and reloaded into the holder and dipped past the cap and body joints into 4\% Eudragit L100 coating solution. Dipping of capsules was repeated with 20\% Eudragit L100 coating solution.

Capsule disintegration test. Individual EPT-containing enteric-coated capsules $(n=5)$ were submerged in $1 \mathrm{~N}$ hydrochloric acid for $2 \mathrm{~h}$ at room temperature. Acid submerging each 
capsule was removed and stored separately. Capsules were washed briefly with sodium phosphate buffer ( $\mathrm{pH}$ 6.0) followed by submersion in sodium phosphate buffer (pH 6.8). Aliquots were removed from each tube following light vortexing at 5, 10, 15, 30, 60, 90, 120, and $180 \mathrm{~min}$ and stored individually. EPT release from individual capsules was analyzed by CTB sandwich ELISA.

CTB sandwich ELISA. The concentration of EPT standard was measured by Nanodrop (Thermo Fisher Scientific). Plates were coated with $100 \mu \mathrm{L}$ per well of $2.5 \mu \mathrm{g} / \mathrm{mL}$ of the rat anti-CTB monoclonal antibody 7A12B3 diluted in PBS. After overnight incubation (16 to $24 \mathrm{~h}$ ) at $4{ }^{\circ} \mathrm{C}$, plates were washed three times with PBST (0.05\% Tween 20 in $1 \mathrm{X}$ PBS) and blocked with a blocking solution (3\% bovine serum albumin, $0.05 \%$ Tween 20 in $1 \mathrm{X}$ PBS) for $2 \mathrm{~h}$ at room temperature, then washed with PBST in triplicate. Three-fold serially diluted, duplicate standard samples $(100 \mu \mathrm{L} /$ well $)$ were added to plates in dilution buffer $(1 \%$ bovine serum albumin, 0.05\% Tween 20 in $1 \mathrm{X}$ PBS). Unknown samples were diluted 1:10 in dilution buffer and added to plates in duplicate $(100 \mu \mathrm{L} /$ well $)$. Samples were incubated on plates for $1 \mathrm{~h}$ at room temperature. Plates were washed and rabbit anti-CTB polyclonal antibody (Abcam; Cambridge, United Kingdom) diluted 1:20,000 in dilution buffer (100 $\mu \mathrm{L} /$ well) was added; plates were then incubated at room temperature for $1 \mathrm{~h}$. Plates were washed and goat anti-rabbit IgG-HRP (Southern Biotech; Birmingham, AL) diluted 1:100,000 in dilution buffer was added, followed by incubation at room temperature for $1 \mathrm{~h}$. Plates were washed a final time and developed with TMB. The reaction was stopped with 2 $\mathrm{N}$ sulfuric acid and the absorbance at $450 \mathrm{~nm}$ was immediately measured with a BioTek plate 
reader. Percent release was determined by extrapolation of calculated EPT concentrations using CTB sandwich ELISA compared to a known fixed mass of $5 \mu \mathrm{g}$ EPT per capsule.

\section{Acute DSS colitis model and EPT treatment for capsule administration study. Groups}

of 10 female C57BL/6 mice, randomly assigned, were used. 3\% DSS (M.W. 36,000 50,000; M.P. Biomedicals, Santa Ana, CA) was administered in drinking water ad libitum for 7 days. Body weights were monitored daily from the start of DSS exposure to sacrifice on day 14. On the last day of DSS exposure, animals were orally gavaged $100 \mu \mathrm{L}$ PBS, 100 $\mu \mathrm{L}$ of EPT powder dissolved in PBS $(0.03 \mathrm{mg} / \mathrm{mL}$ solution) after administration of sodium bicarbonate $(200 \mu \mathrm{L}$ of $30 \mathrm{mg} / \mathrm{mL}$ solution) as described previously, or enteric coated capsules filled with $3 \mu \mathrm{g}$ EPT (described above) [14]. Animals recovered with normal drinking water for 7 days. Disease activity index (DAI) scores, consisting of body weight loss, fecal consistency and occult blood tests, were recorded following sacrifice and performed as previously described [51]. Distal colon tissues were fixed in neutral buffered formalin and stained with hematoxalin and eosin (H\&E). Histopathological scores, a combination score comprised of crypt architecture, inflammatory infiltrate, muscle thickening and goblet cell presences scores, were determined as previously described [52, 53]. Each category was ranked on a scale from 0 to 3 and summed to obtain a single histopathological damage score for each tissue.

Statistics. For all data, outliers were determined by statistical analysis using the Grubb's test and excluded from further analysis if $P<0.05$. Graphs were prepared and analyzed using Graphpad Prism version 5.0 (Graphpad Software, La Jolla, CA). To compare two data sets, 
an unpaired, two-tailed Student's $t$ test was used. To compare three or more data sets, oneway ANOVA with Bonferroni's multiple-comparison post-test was used. 


\section{CHAPTER III: RESULTS}

\subsection{EPT at an intracolonic dose of $0.1 \mu \mathrm{M}$ is most effective at mitigating acute DSS-induced colitis.}

To evaluate the efficacy of EPT and determine an optimal target dose for clinical studies, a dose level analysis was performed using an acute DSS colitis mouse model. Female C57B1/6 mice (8 weeks old) were exposed to 3\% DSS ad libitum in drinking water for 7 days. Immediately upon DSS cessation mice were intracolonically administered $100 \mu \mathrm{L}$ PBS, $0.01 \mu \mathrm{M} \mathrm{EPT}, 0.1 \mu \mathrm{M}$ EPT, or $1 \mu \mathrm{M}$ EPT (corresponding to $0.0614 \mu \mathrm{g}, 0.614 \mu \mathrm{g}$, or $6.14 \mu \mathrm{g}$ per animal). All animals were monitored an additional 5 days following dosing. Among the three dose levels tested, $0.1 \mu \mathrm{M}$ EPT was the only dose that decreased disease activity index (DAI) scores in a statistically significant manner (Figure 1A). Although not statistically significant, treatment with $1 \mu \mathrm{M}$ and 0.01 $\mu \mathrm{M}$ EPT slightly decreased DAI scores. Histopathological assessment was performed to corroborate the aforementioned DAI results. Similar to the DAI results, histopathological damage scores indicate that $0.1 \mu \mathrm{M}$ EPT was the most effective dose to mitigate DSSinduced acute colitis (Figure 1B). Interestingly, $0.01 \mu \mathrm{M}$ EPT treatment was also sufficient to ameliorate histological damage compared to PBS-treated mice. Treatment with $1 \mu \mathrm{M}$ EPT trended to a decreased histological damage score than the PBS group, however, these results were not statistically significant. 

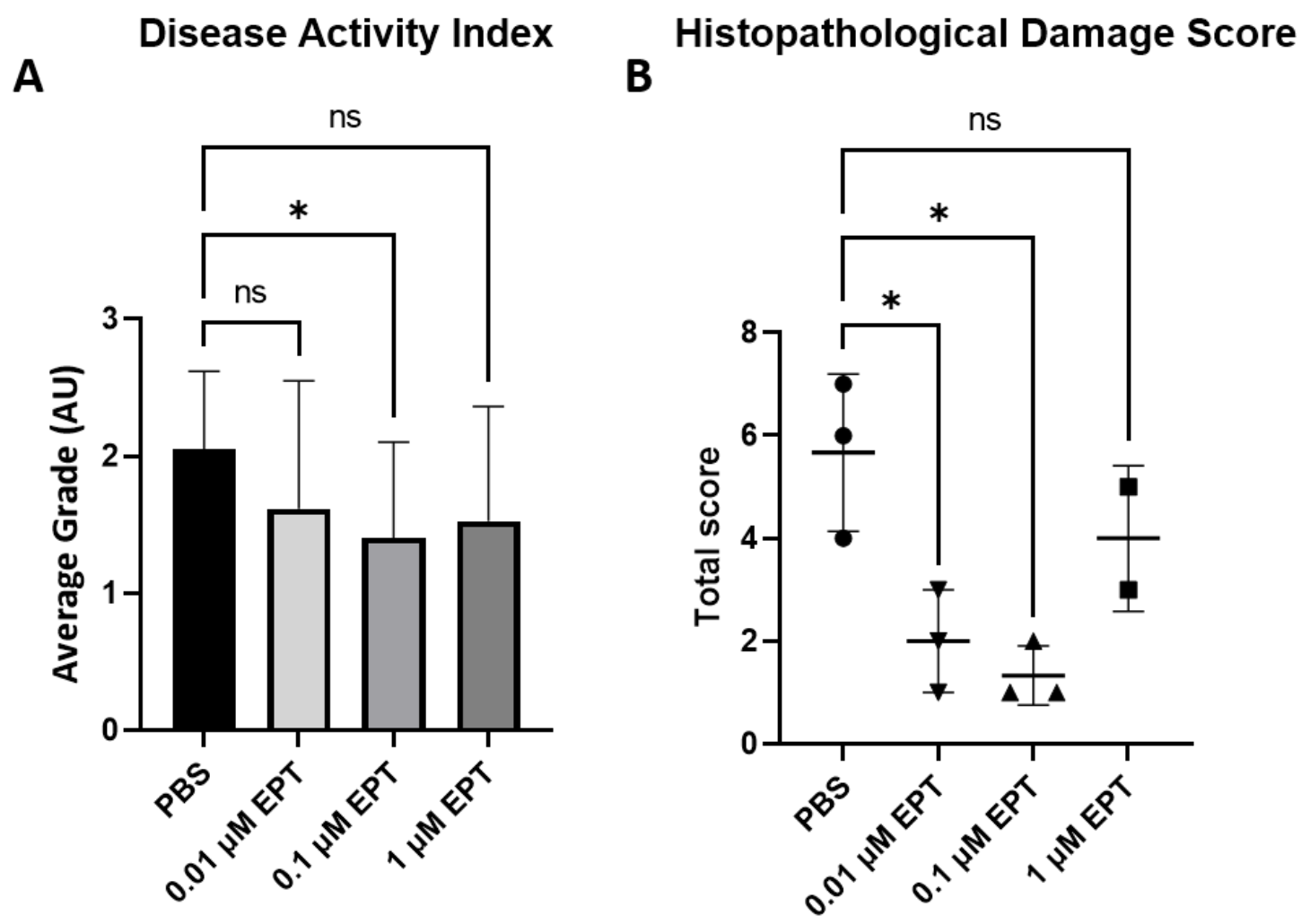

Figure 1. Dose level analysis of intracolonic administration of EPT. Treatment with $0.1 \mu \mathrm{M}$ EPT is most effective at mitigating DAI and histopathological damage scores in acute DSS colitis. (A) DAI scores of each treatment group in the DSS acute colitis study. DAI is an average score consisting of body weight, stool consistency, and blood in stool at time of sacrifice. (B) Histopathological damage scores of each treatment group in the DSS acute colitis study. Histopathological damage score is a cumulative score consisting of crypt architecture, inflammatory infiltrates, muscle thickening, and goblet cell depletion from H\&E-stained crosssections of distal colon tissue. Mean $\pm \mathrm{SD}$ is displayed. $* P<0.05$, one-way ANOVA with Bonferroni's multiple comparisons test.

Administration of $0.1 \mu \mathrm{M}$ EPT most effectively protected mice from histological damage in the distal colon compared to 0.01 or $1 \mu \mathrm{M}$ EPT (Figure 2). Treatment with 0.1 $\mu \mathrm{M}$ EPT decreased the prevalence and incidence of crypt loss and structural alterations, immune cell infiltrates, and goblet cell depletion compared to $0.01 \mu \mathrm{M}$ EPT, $1 \mu \mathrm{M} \mathrm{EPT,}$ and PBS groups. Dosing with $0.01 \mu \mathrm{M}$ EPT protected from goblet cell depletion and immune cell infiltrates, however, crypt loss and structural alterations were more common 


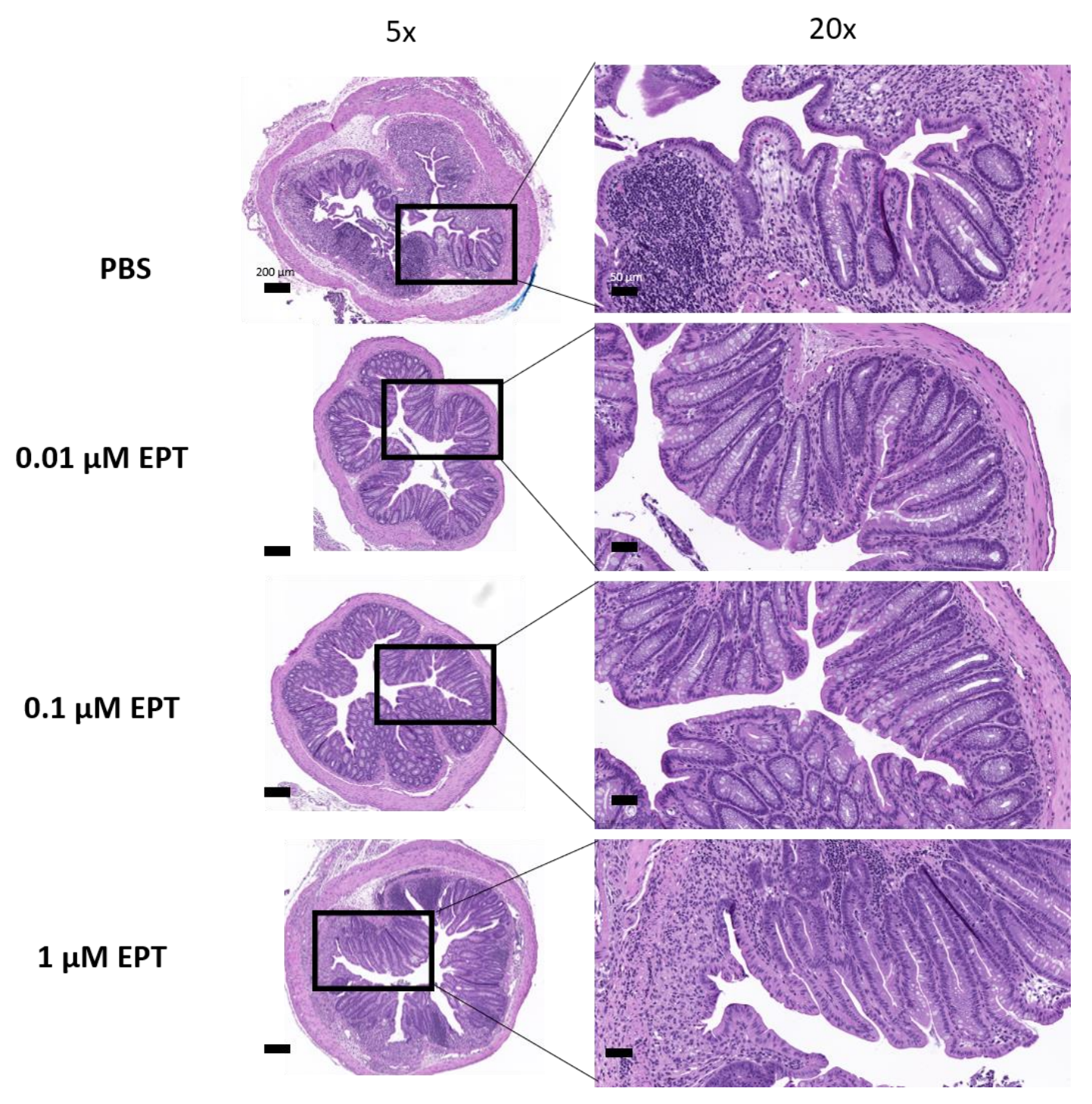

Figure 2. Effects of intracolonic treatment with EPT on mice colon histological alterations induced by DSS. Mice in the $0.1 \mu \mathrm{M}$ dose group were more protected from crypt loss, inflammatory cell infiltration, and goblet cell depletion than any other group. Representative 5x (left) and 20x (right) photomicrographs of H\&E-stained distal colon tissues from each treatment group.

in these tissues than the $0.1 \mu \mathrm{M}$ EPT group. Treatment with $1 \mu \mathrm{M}$ EPT decreased incidences of crypt loss, immune cell infiltrates and goblet cell depletion compared to control, but these effects were much less pronounced than in the 0.01 and $0.1 \mu \mathrm{M}$ EPT dosing groups. 


\subsection{Pre-formulation analysis of a prototype oral formulation of EPT.}

Buffers and excipients were screened to determine a combination producing optimal EPT powder. This was determined by assessing pentamer disassembly into monomer, residual moisture, yield, and solubility of powder in water, with a target product profile $(\mathrm{TPP})$ of $<5 \%$ monomer, $<10 \%$ moisture, and $100 \pm 10 \%$ solubility

(Table 1). Of the buffers tested, PBS and PBS + $100 \mathrm{mM}$ mannitol were chosen from the screened buffers based on the TPP values set for the aforementioned parameters. To assess stability of the chosen buffers, pentamer degradation and water-solubility of EPT formulated in PBS or PBS + $100 \mathrm{mM}$ mannitol were analyzed over a period of three weeks (Table 2). The screened and finalized drying conditions are summarized in Table 3. Given the importance of pentamer stability to the epithelial repair activity of EPT [30],

\section{Table 2.}

$\underline{\text { Stability of EPT powder in chosen buffer excipients. }}$

\begin{tabular}{lcc}
\hline \multicolumn{1}{c}{ Buffer } & \% Monomer & \% Solubility \\
\hline PBS & 4.9 & 106 \\
PBS, 100 mM Mannitol & 3.1 & 97 \\
\hline & 1 Week & 110 \\
\hline PBS & 5.9 & 97 \\
PBS, 100 mM Mannitol & 4.0 & 110 \\
\hline & 2 Weeks & 99 \\
\hline PBS & 4.8 & \\
\hline PBS, 100 mM Mannitol & 3.3 & 110 \\
\hline PBS & 3 Weeks & 99 \\
\hline
\end{tabular}


PBS $+100 \mathrm{mM}$ mannitol was used to optimize drying conditions and subsequent experiments. A variety of inlet and outlet temperature range combinations were assessed to determine which would result in optimal pentamer stability. A lower inlet temperature range $\left(116-122^{\circ} \mathrm{C}\right)$ and higher outlet temperature range $\left(64-67^{\circ} \mathrm{C}\right)$ were found to result in the lowest degree of pentamer degradation. Therefore, these conditions were utilized for subsequent batch productions.

\section{Table 3}

Optimization of spray-dry parameters.

\begin{tabular}{|c|c|c|c|c|c|c|c|c|}
\hline Buffer & $\begin{array}{c}\% \\
\text { Monomer }\end{array}$ & $\begin{array}{c}\% \\
\text { Moisture }\end{array}$ & $\begin{array}{c}\% \\
\text { Solubility }\end{array}$ & $\begin{array}{l}\text { Q- } \\
\text { flow } \\
\text { (min) }\end{array}$ & $\begin{array}{l}\text { Inlet } \\
\left({ }^{\circ} \mathrm{C}\right)\end{array}$ & $\begin{array}{l}\text { Outlet } \\
\left({ }^{\circ} \mathrm{C}\right)\end{array}$ & $\begin{array}{c}\text { Aspirator } \\
(\%)\end{array}$ & $\begin{array}{l}\text { Pump } \\
(\%)\end{array}$ \\
\hline PBS & 12.3 & 9.7 & 97 & - & 121 & $\begin{array}{c}66- \\
67\end{array}$ & 90 & 20 \\
\hline PBS & 8.0 & 3.7 & 99 & - & 120 & $\begin{array}{l}61- \\
64\end{array}$ & 90 & 20 \\
\hline PBS & 4.9 & 2.9 & 106 & 35 & $\begin{array}{c}118- \\
125\end{array}$ & $\begin{array}{c}61- \\
65\end{array}$ & 90 & 20 \\
\hline PBS & 11 & - & 99 & 34 & $\begin{array}{c}121- \\
123\end{array}$ & $\begin{array}{c}61- \\
63\end{array}$ & 90 & 20 \\
\hline $\begin{array}{l}\text { PBS, } 100 \mathrm{mM} \\
\text { Mannitol }\end{array}$ & 3.1 & 0 & 97 & 35 & $\begin{array}{c}120- \\
123\end{array}$ & $\begin{array}{l}62- \\
64\end{array}$ & 90 & 20 \\
\hline $\begin{array}{l}\text { PBS, } 100 \mathrm{mM} \\
\text { Mannitol }\end{array}$ & 9 & - & 119 & 34 & $\begin{array}{c}121- \\
124\end{array}$ & $\begin{array}{c}63- \\
66\end{array}$ & 90 & 20 \\
\hline $\begin{array}{l}\text { PBS, } 100 \mathrm{mM} \\
\text { Mannitol* }^{*}\end{array}$ & 1.0 & 9.5 & 97 & 35 & $\begin{array}{c}116- \\
122\end{array}$ & $\begin{array}{l}64- \\
67\end{array}$ & 90 & 20 \\
\hline $\begin{array}{c}\text { PBS, } 100 \text { mM } \\
\text { Mannitol @ } \\
\text { 5mg/mL* }\end{array}$ & 1.1 & 4.9 & 96 & 35 & $\begin{array}{l}118- \\
122\end{array}$ & $\begin{array}{l}61- \\
63\end{array}$ & 90 & 20 \\
\hline \multicolumn{9}{|c|}{ *Finalized drying conditions } \\
\hline
\end{tabular}

\subsection{Stability and disintegration testing of EPT capsules.}

To demonstrate the stability of the chosen prototype EPT powder immediately after spray-drying we performed a GM1/KDEL-ELISA and SEC-HPLC to detect the 
presence of intact KDEL sequence and the conformational state of CTB pentamer, which are crucial for the mucosal healing activity of EPT $[11,30]$. This immunoassay and analytical analysis were repeated at 9 months post-spray dry with EPT powder stored under desiccation at $23^{\circ} \mathrm{C}$ in parafilm-wrapped tubes. GM1/KDEL-ELISA results demonstrate that GM1 binding affinity of spray dried EPT was unchanged after drying (Figure 3A) and 9 months post-drying when stored under desiccation at $23^{\circ} \mathrm{C}($ Figure 3B). SEC-HPLC chromatograms illustrate the stability of EPT pentamers in 9 months post-drying (Figure 3). The small peak of $8.2 \%$ at a retention time of $\sim 18.5 \mathrm{~min}$ correlates to EPT monomers (see Figure S1), indicating only slight pentamer degradation after 9 months post-drying stored under desiccation at $23^{\circ} \mathrm{C}$ (Figure3D).
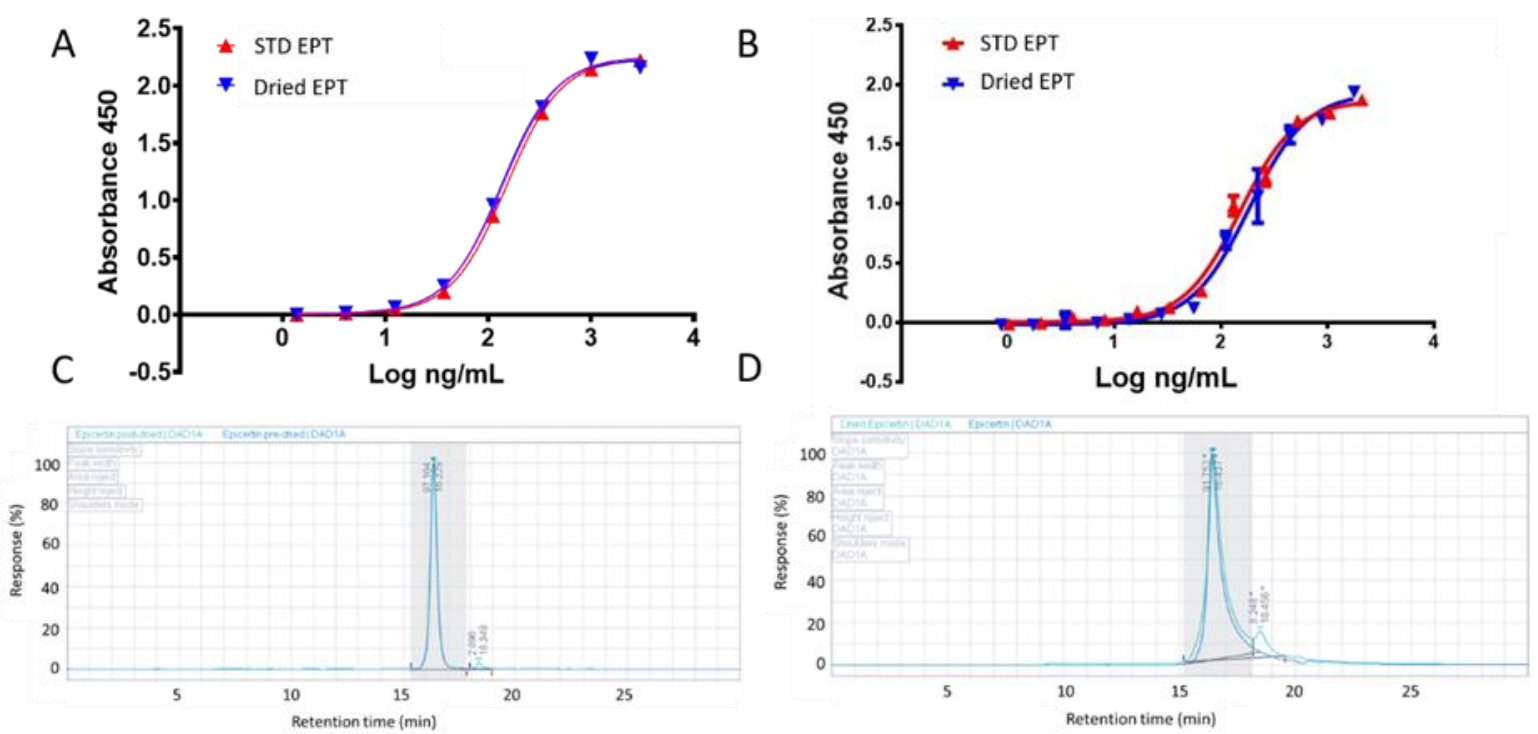

Figure 3. Stability assessment of spray dried EPT. The production of EPT standard is described in the methods section. The stability of dried EPT post-drying and after 9 months was assessed by GM1-capture KDEL-detection ELISA and SEC-HPLC. A representative binding curve of spray dried EPT is shown for (A) one day post-drying and (B) after 9 months stored at $23^{\circ} \mathrm{C}$ in a desiccator, compared to an EPT standard. SECHPLC chromatogram of (C) non-dried EPT (blue) and EPT one day post-drying (green) and (D) dried EPT (green) after 9 months stored at $23^{\circ} \mathrm{C}$ in a desiccator (EPT standard is in blue). After 9 months dried EPT contained $91.8 \%$ pentamer and $8.2 \%$ monomer 
Following packing of EPT powder into gelatin capsules and coating with an enteric coating solution, $\mathrm{pH}$-dependent release of EPT was assessed by a capsule disintegration assay. Capsules were coated with Eudragit S100 coating solution to prevent the release of EPT prior to arrival at the proximal colon where the intraluminal $\mathrm{pH}$ has increased to $\sim \mathrm{pH} 6.8$ after transiting through the stomach and small intestine [54, 55]. The capsule disintegration assay simulated passage of the capsule through gastric acid and allowed us to analyze the release profile of EPT following exposure to $\mathrm{pH} 6.8$.

Recovery of EPT from capsules was determined by a CTB detection sandwich ELISA, which has the capacity to detect both GM1-binding pentamer and disassembled CTB molecular species unlike GM1-capture ELISA (Figure 4), as EPT dissociation
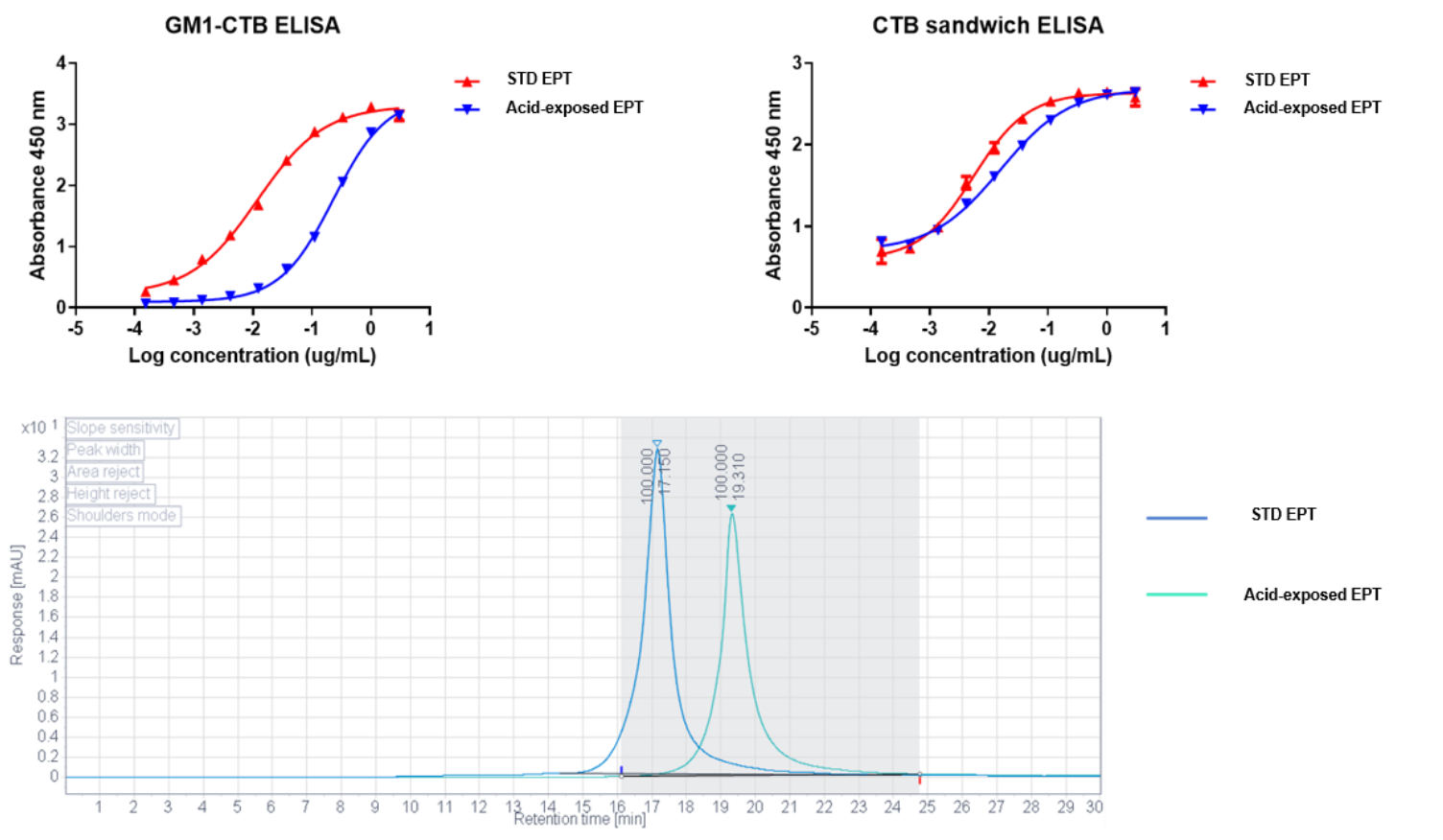

Figure 4. Methodology to detect pentamer versus monomer EPT. Top left: GM1-CTB ELISA. STD EPT in pentamer has a much higher EC50 to GM1 than acid exposed EPT which contains EPT in monomer form. Top right: CTB sandwich ELISA. STD EPT in pentamer form and acid exposed EPT monomer form can be detected in a similar manner demonstrating capacity to detect both GM1-binding pentamer and disassembled CTB molecular species. Bottom: Size Exclusion (SEC)-HPLC. STD EPT elutes in pentamer form at a 17.1-minute retention time whereas acid exposed EPT elutes in monomer form at 19.3 minutes, whereby demonstrating acid dissociates pentamer EPT into monomer EPT. 
could occur if the capsule content was prematurely discharged and exposed to low $\mathrm{pH}$ conditions (Figure 4). The data revealed that EPT was released from the polymer-coated capsules in a pH-dependent manner (Figure 5). No EPT was detectable at pH 1.0, suggesting that the enteric coating prevented the release of EPT from capsules prior to expected release at $\mathrm{pH}$ 6.8. The same coating solution and method was used to prepare capsules used in the following acute colitis model.

\subsection{Efficacy of EPT enteric-coated capsules in an acute colitis model.}

The efficacy of EPT delivered by this oral capsule formulation was assessed compared to standard EPT in an acute DSS colitis mouse model $[14,30]$. In this model, animals were exposed to $3 \%$ DSS ad libitum in drinking water for 7 days at which time mice were

\section{EPT release from capsules}

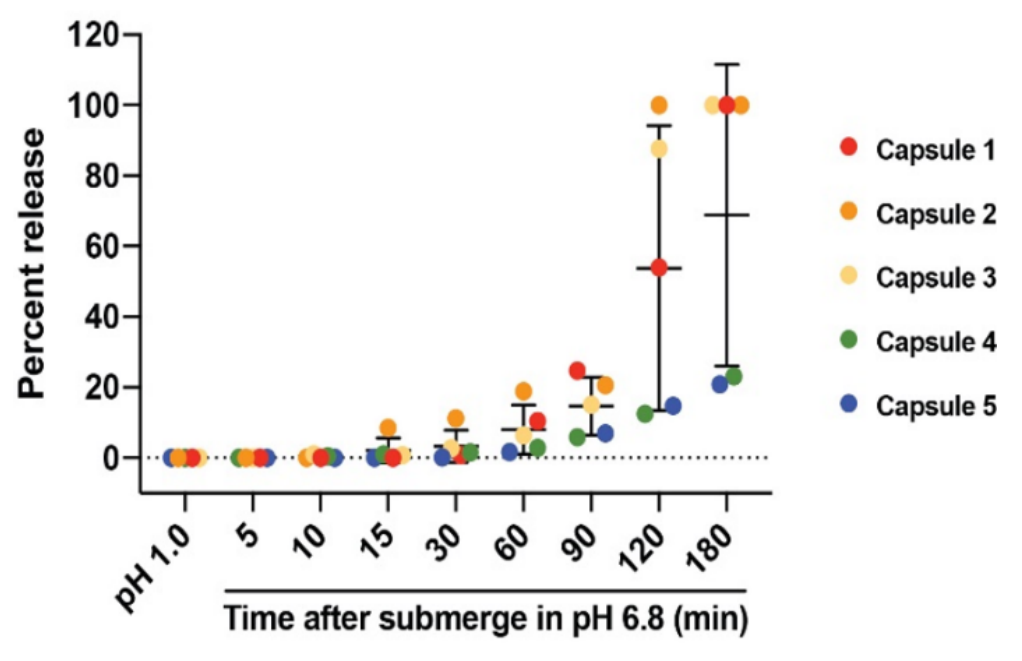

Figure 5. EPT released from enteric-coated capsules is $\mathrm{pH}$-dependent. Release of EPT was measured by CTB sandwich ELISA. EPT releases from capsules only after submersion at $\mathrm{pH}$ 6.8. Percent of EPT release from capsules after $2 \mathrm{~h}$ submersion in $0.1 \mathrm{~N} \mathrm{HCl}$, and at $\mathrm{t}=5,10,15,30,60,90,120$, and $180 \mathrm{~min}$ after $\mathrm{pH}$ shift to 6.8. $\mathrm{N}=5$. Percent release was determined by extrapolation of calculated EPT concentrations using CTB sandwich ELISA compared to a known fixed mass of $5 \mu \mathrm{g}$ EPT per 


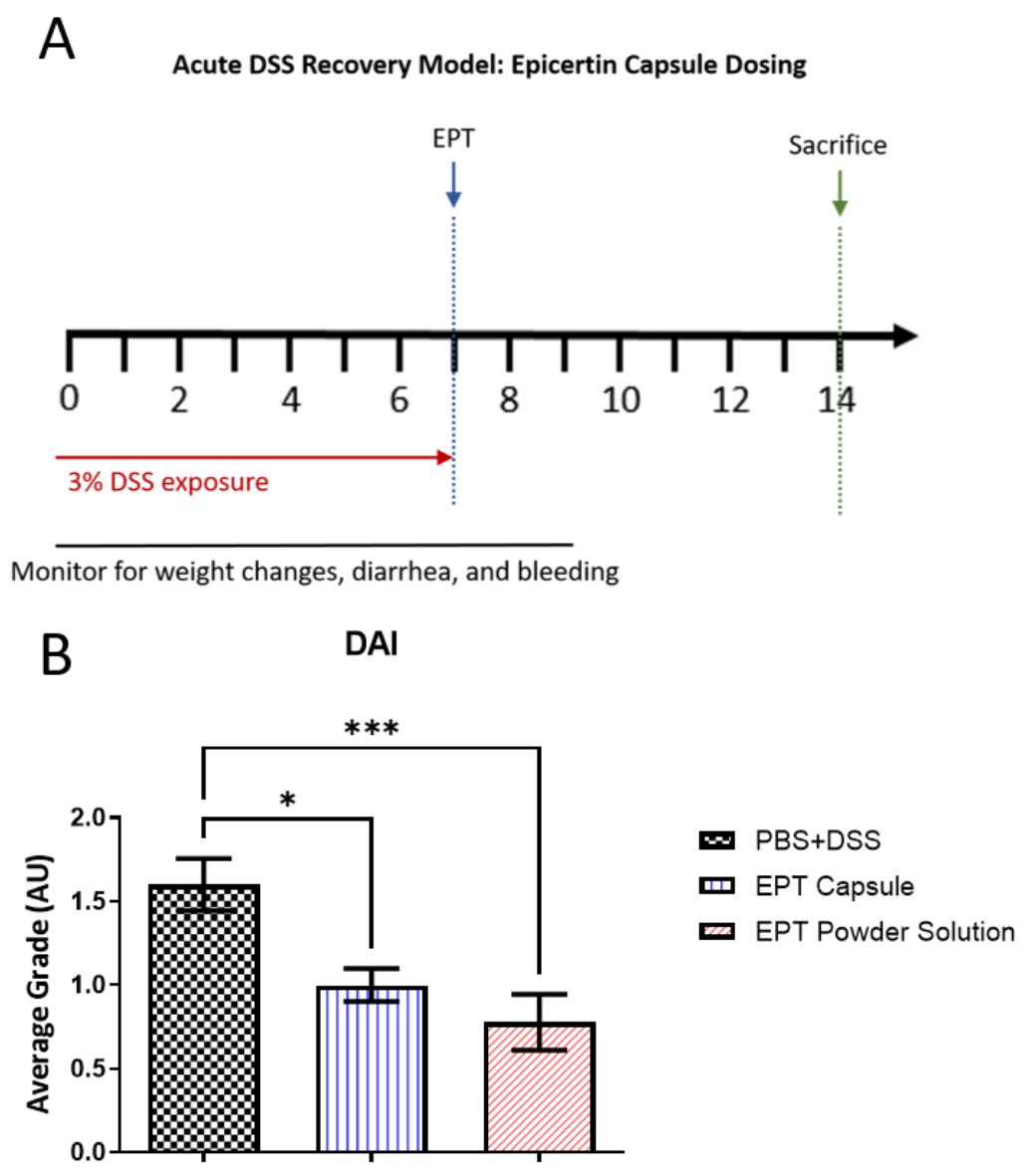

Figure 6. Enteric-coated EPT capsules mitigate acute DSS colitis in mice. (A) Study design. (B) Mice were dosed with an EPT capsule $(\mathrm{N}=10)$, pre-dissolved EPT powder following gastric acid neutralization (EPT powder solution; N=9), or capsule vehicle control $(\mathrm{N}=10)$ on day 7 following DSS exposure. DAI scores were determined on day 14 as a combined measure of body weight recovery, stool consistency, and blood in stool; data are shown as mean \pm SEM. $* P<0.05$, *** $P<$ 0.001, one-way ANOVA with Bonferroni's multiple comparisons test.

dosed $5 \mu$ g resuspended dried EPT (EPT powder solution) or PBS via oral gavage after administration of sodium bicarbonate. A third group of mice were dosed with an entericcoated capsule containing $5 \mu \mathrm{g}$ EPT with no administration of sodium bicarbonate. All animals were monitored an additional 7 days following DSS cessation. Compared to PBS, DAI scores were decreased in mice administered a EPT capsule directly as well as sodium bicarbonate followed by reconstituted EPT powder (Figure 6). To corroborate 

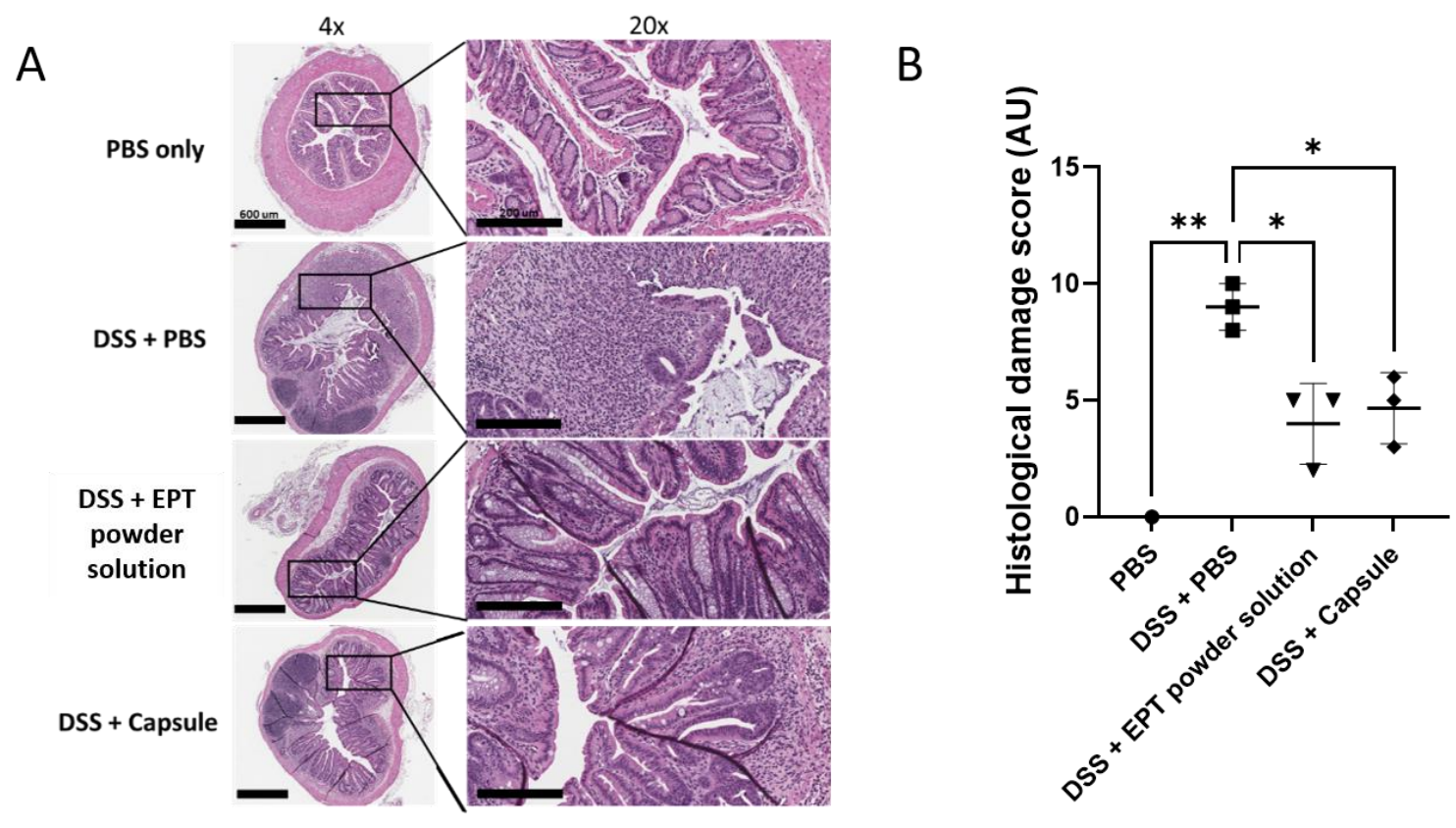

Figure 7. Treatment with encapsulated EPT mitigates acute colitis in mice.

Encapsulated EPT (DSS + Capsule) treatment protected mice from histological damage similarly to treatment with EPT powder solution following gastric acid neutralization (DSS + EPT powder solution). (A) Representative 4x (left) and 20x (right) photomicrographs of $\mathrm{H} \& \mathrm{E}$-stained distal colon tissues from each treatment group. (B) Histological damage scores of each treatment group in the DSS acute colitis study. $* P<0.05,{ }^{*} P<0.01$; one-way ANOVA with Bonferroni's multiple comparisons test.

the aforementioned results, we performed a histopathological evaluation to assess the presence of hallmark colitis markers, such as alterations in crypt height and loss, epithelial barrier disruption, and immune cell infiltration, in hematoxalin and eosin (H\&E) stained tissues. EPT powder solution administration following gastric acid neutralization and encapsulated EPT similarly protected mice from DSS-induced acute colitis. Treatment with EPT by capsule administration or oral gavage following gastric acid neutralization protected mice from crypt loss and distortion, inflammatory cell infiltrates, muscle thickening, and goblet cell loss (Figure 7A, B). However, few crypt structural alterations, primarily crypt branching, were noted in tissues from both EPT 
treatment groups. Taken together, these results support equivalence between EPT treatment in solution following acid neutralization and encapsulated EPT treatment. 


\section{CHAPTER IV: DISUSSION}

EPT is a recombinant variant of the nontoxic component of the cholera toxin that exhibits unique mucosal healing activity in the colon $[14,30,56]$. Previous studies examining the therapeutic potential of EPT in mouse colitis models have primarily focused on one route of administration: oral gavage. An issue with this route of administration, however, is the need to neutralize gastric acid with sodium bicarbonate prior to gavage as CTB is acid labile. This is a drawback when moving forward with development of EPT as a therapeutic for UC and determining a final drug product formulation. Although oral agents are typically preferred by patients undergoing treatment for chronic diseases such as UC, gastric acid neutralization requirements could potentially affect patient outcomes by lowering adherence and ease of administration. Alternatively, we have shown that EPT also has mucosal healing activity when administered intracolonically. Although not necessarily the ideal formulation for a chronic disease, enemas are quite commonly used for the treatment of UC. Further, the development of an oral formulation for an acid labile protein like EPT could slow down efforts to begin first-in-human safety trials as more investigation and optimization is needed to achieve production on an industrial scale. To this end, we aimed to establish an intracolonic target dose for first-in-human trials as well as develop a prototype solid oral formulation for that would allow EPT to circumvent gastric acid degradation and allow for topical administration to affected areas. We described herein an encapsulated spraydried drug substance coated with an enteric coating to allow for $\mathrm{pH}$-dependent release of 
EPT at the colon. This oral formulation will undergo continued development and optimization while we move forward with a topical formulation.

The dose level analysis study described here allowed our group to identify a target intracolonic dose of EPT. Establishing a target intracolonic dose of EPT is crucial to justify the study design of a Phase I trial. Previous studies assessing mucosal healing by topical delivery of EPT were primarily focused on a concentration of $1 \mu \mathrm{M}$, however, a small study hinted at the efficacy of $0.1 \mu \mathrm{M}$ (data not shown). Therefore, we elected to compare the effects of $0.01,0.1$ and $1 \mu \mathrm{M}$ (corresponding to $0.0614,0.614$, and 6.14 $\mu \mathrm{g} /$ animal, respectively) in an acute DSS colitis model. The DAI and histological results indicate that $0.1 \mu \mathrm{M}$ is the ideal target intracolonic dose of those tested. Although all doses of EPT led to a trending decrease in DAI scores, this difference was only significant in the $0.1 \mu \mathrm{M}$ treatment group (Figure 1A). Similarly, treatment with 0.01 or $0.1 \mu \mathrm{M}$ EPT, but not $1 \mu \mathrm{M}$, significantly decreased histopathological scores (Figure 1B). It is currently unknown as to why EPT does not seem to induce mucosal healing in a dose-dependent manner, however, a possibility could lie in the ability of EPT to induce an unfolded protein response (UPR).

The UPR is activated in response to ER stress to ensure protein folding fidelity and maintain ER functions [57]. There are three main signaling pathways of the UPR initiated by ER transmembrane protein sensors: IRE1 $\alpha$, PERK, and ATF6 $\alpha$. The UPR is commonly cited as a means for apoptosis of cells under chronic stress; however, recent literature has described the necessity of the UPR to intestinal homeostasis and epithelial barrier function $[34,35,58,59]$. We previously demonstrated that a UPR is crucial in the induction of mucosal healing following treatment with EPT [30]. One possible 
explanation for the decrease in efficacy with $1 \mu \mathrm{M}$ EPT treatment is an overwhelming of the UPR leading to apoptosis. Oral gavage of $3 \mu \mathrm{g}$ EPT alleviates DSS colitis in mice, which is believed to be facilitated by an EPT-induced UPR. However, a $1 \mu \mathrm{M}$ dose of EPT corresponds to $6.14 \mu \mathrm{g}$ : this is more than twice the oral gavage dose. Since the UPR often results in cell death upon overwhelming ER stress, it would be plausible that too high of a dose of EPT could trigger this pathway rather than inducing just enough of a response to maintain homeostasis. A limitation of this theory is the fact that a treatment with $1 \mu \mathrm{M}$ EPT still slightly decreased DAI and histopathological damage scores. If this concentration of EPT were causing UPR-induced cell death, it would be thought that disease severity would be constant, or even exacerbated, compared to PBS-treated mice. Future studies assessing the extent of UPR upregulation following treatment with 0.01 , 0.1 , and $1 \mu \mathrm{M}$ EPT could shed some light on this interesting phenomenon.

The most important insight gained from this dose-analysis study was the identification of $0.1 \mu \mathrm{M}$ as the target intracolonic dose of EPT. Establishing a target dose is critical in designing future toxicology assessments and in the development of an Investigational New Drug (IND) application. While continuing to move forward with a topical formulation of EPT, we sought to begin investigation into potential oral formulations for future drug product development.

A major technical advance made in the present study towards a solid oral formulation is the establishment of the method of drying the drug substance. Drying of pharmaceuticals is a long-implemented practice commonly used to enhance final drug product for a variety of purposes; examples of the benefits of biopharmaceutical dehydration include handling and storage improvement, decrease in transportation cost, 
improved stability and aid in development of modified or delayed release particles [47, 50]. It is known that proteins are more stable in solid rather than liquid form [60-63]. Use of solid formulations can greatly increase shelf-life and reduce storage regulations, saving patients and manufacturers money in lost production costs due to expired product. Further, oral capsules filled with dried protein may be coated with a time- or $\mathrm{pH}-$ dependent coating to allow for targeted release in the GI tract [47]. This is especially useful when administering CTB orally as it allows for release at the affected site. Without this coating, orally administered pentameric CTB would degrade into nonfunctional monomers upon exposure to the stomach acid. Dehydrating CTB is one solution to this issue.

Previously, CTB has been dehydrated by a variety of methods. A freeze-dried inactivated whole-cell oral cholera vaccine was formulated in attempts to optimize delivery of mass quantities of vaccine to low-income countries [7]. This formulation elicited strong serum and gut mucosal anti-LPS antibody responses in immunized mice; these responses were comparable to those achieved with equivalent liquid formulation [7]. The dry formulation is beneficial in substantially reducing package volumes and weights when delivering product to areas in need of mass vaccination. Further, CTB has been successfully spray-dried in the form of heat-killed Vibrio cholerae-containing microparticles [64]. We utilized the benefits of the spray-drying process with EPT to develop a more optimal oral formulation of the protein. When a protein is spray-dried, conditions need to be tailored to the protein being dried since materials undergo some thermal stress which can result in protein degradation; hence, identification of ideal heating conditions is critical. CTB pentamer degradation occurs approximately between 
66 and $78^{\circ} \mathrm{C}[3,65,66]$. Therefore, we screened outlet temperature ranges between 61 and $67^{\circ} \mathrm{C}$ to maintain stability of functional EPT pentamer. Since we achieved optimal TPP parameters with outlet temperatures closer to $67^{\circ} \mathrm{C}$, testing outlet temperatures closer to $78^{\circ} \mathrm{C}$ could possibly result in a further improved powder by solubility or moisture content. The most relevant source of stress during spray-drying results from the dehydration process, therefore the addition of excipients to the liquid solution prior to spray drying is crucial to replace the hydrogen bonding that exists in an aqueous environment [47]. In this study, a screen was developed to identify optimal excipient conditions to improve target profile parameters.

A buffer and excipient screen to produce an ideal dried EPT powder based on a set TPP (< 5\% monomer, $<10 \%$ moisture, and $100 \pm 10 \%$ solubility). Addition of a common excipient (mannitol) decreased the presence of EPT monomer from approximately 5\% to 3\% (Table 2, 3). It is unsurprising that addition of mannitol improved stability of EPT pentamer, as it is often used in dried pharmaceuticals due to its thermostability [67-69]. PBS + 100 mM mannitol outperformed all other screened buffers in the aforementioned TPP categories and was therefore chosen as the formulation buffer. All TPP categories were met, however, loss of drug product was a consistent problem as $70 \%$ was the maximum recovery among all buffers tested (data not shown). Other studies using this particular spray drier consistently report yields below 50\% [70]. Although one issue with this instrument is in aspects of the design, another manageable issue is identifying an ideal inlet to outlet temperature ratio for the protein of interest [70]. This limitation allows room for improvement moving forward in formulation development. Stability of EPT powder produced in the chosen buffer was confirmed by measuring 
monomer content and percent solubility each week for a total of three weeks (Table 2, 3). Low hygroscopicity of mannitol likely had a positive impact on moisture content; it is known that mannitol is an ideal excipient to minimize moisture in a dried formulation $[68,69]$. Monomer content and solubility remained stable around $3 \%$ and $98 \%$, respectively, over the course of three weeks. Mannitol seems to have a protective effect on EPT pentamers, possibly due its thermostability. This study, however, lacked investigation of lactose as a potential excipient. Lactose is the most commonly utilized excipient in spray drying $[67,71]$. Mannitol and lactose are both attractive excipients as they are soluble in water and are non-toxic. Lactose has an advantage to mannitol as it is more economical, although it should be noted that lactose has a higher hygroscopicity which can hinder stability of the dried product [67, 69]. Further, lactose is more likely to react with active pharmaceutical ingredients as it is a reducing sugar, whereas mannitol exhibits a strong inertness [67].

Upon selection of buffer composition, spray dry parameters were further investigated. Spray dry parameters were optimized by screening a combination of inlet and outlet temperatures to determine a combination producing EPT powder with the best possible TPP values (Table 3). It has been suggested that a high inlet temperature to outlet temperature ratio might be the key to maximizing yield . Our results are consistent with this claim as the highest inlet:outlet temperature condition tested achieved optimal TPP values (Table 3). We also demonstrated via SEC-HPLC and GM1-KDEL detection ELISA that spray dried EPT maintains GM1 binding affinity and remains stable under dry conditions for up to 9 months (Figure 4). This combination of factors indicates that 
EPT powder encapsulated immediately post-dry and after 9 months should exhibit similar effects upon administration.

The oral formulation presented here was designed for direct delivery of EPT to the target site by utilizing an anionic polymer coating that makes $\mathrm{pH}$-dependent release at the colon possible. The in vitro disintegration test suggested that not all capsules released $100 \%$ of encased EPT (Figure 5). It is possible that there are inconsistencies in the thickness of the enteric coating around the capsules, leading to variations in release profiles. The combination of dipping capsules by and viscosity of the solution could lead to disparities between capsule coatings. This could be ameliorated by coating the capsules using an automated system that would likely be utilized when coating capsules at an industrial scale. Further, it was observed during disintegration testing that capsules tend to fold in on themselves when free-floating in solution. This is an unlikely issue in vivo as movement through the GI tract would prevent the folding over of capsules. In support of this hypothesis, the acute DSS study showed that the enteric-coated EPT capsule ameliorated acute DSS-induced colitis, indicating that the protein was successfully released from the capsules at the site of mucosal damage (Figure 6, 7). The histopathological results described here are also consistent with previous findings in acute and chronic DSS colitis studies evaluating EPT treatment [14, 30, 36]. Taken together, these results support further development of the capsule formulation described herein as this treatment does not require gastric acid neutralization, which would theoretically ease difficulty of administration and boost patient adherence in UC patients. 


\section{CHAPTER V: CONCLUSIONS}

The present studies support an established target dose of $0.1 \mu \mathrm{M}$ for topical administration and continued development of a capsule formulation of EPT. More investigation is needed to uncover the lack of a dose-dependent response following EPT treatment, as this missing piece could be vital to fully elucidating its mechanism of action. The prototype oral formulation described here was effective at alleviating DSSinduced acute colitis but requires further optimization, primarily of the capsule coating technique. Taken together, these results support continued development of EPT as a therapeutic agent of UC. 


\section{REFERENCES}

1. Lönnroth, I. and J. Holmgren, Subunit structure of cholera toxin. J Gen Microbiol, 1973. 76(2): p. 417-27.

2. Sánchez, J. and J. Holmgren, Cholera toxin structure, gene regulation and pathophysiological and immunological aspects. Cell Mol Life Sci, 2008. 65(9): p. 1347-60.

3. Zhang, R.G., et al., The 2.4 A crystal structure of cholera toxin B subunit pentamer: choleragenoid. J Mol Biol, 1995. 251(4): p. 550-62.

4. Wernick, N.L., et al., Cholera toxin: an intracellular journey into the cytosol by way of the endoplasmic reticulum. Toxins (Basel), 2010. 2(3): p. 310-25.

5. Royal, J.M. and N. Matoba, Therapeutic Potential of Cholera Toxin B Subunit for the Treatment of Inflammatory Diseases of the Mucosa. Toxins, 2017. 9(12): p. 379.

6. $\quad$ Baldauf, K.J., et al., Cholera toxin B: one subunit with many pharmaceutical applications. Toxins (Basel), 2015. 7(3): p. 974-96.

7. Borde, A., et al., Preparation and evaluation of a freeze-dried oral killed cholera vaccine formulation. Eur J Pharm Biopharm, 2011. 79(3): p. 508-18.

8. Bergquist, C., et al., Intranasal vaccination of humans with recombinant cholera toxin B subunit induces systemic and local antibody responses in the upper respiratory tract and the vagina. Infect Immun, 1997. 65(7): p. 2676-84.

9. Jertborn, M., et al., Local and systemic immune responses to rectal administration of recombinant cholera toxin B subunit in humans. Infect Immun, 2001. 69(6): p. 4125-8.

10. Kozlowski, P.A., et al., Comparison of the oral, rectal, and vaginal immunization routes for induction of antibodies in rectal and genital tract secretions of women. Infect Immun, 1997. 65(4): p. 1387-94.

11. Morris, D.A., et al., Isolation and detection of a KDEL-tagged recombinant cholera toxin B subunit from Nicotiana benthamiana. Process Biochemistry, 2021. 101: p. 42-49.

12. Hamorsky, K.T., et al., Rapid and scalable plant-based production of a cholera toxin B subunit variant to aid in mass vaccination against cholera outbreaks. PLoS Negl Trop Dis, 2013. 7(3): p. e2046.

13. Hamorsky, K.T., et al., $N$-glycosylation of cholera toxin B subunit in Nicotiana benthamiana: impacts on host stress response, production yield and vaccine potential. Sci Rep, 2015. 5: p. 8003.

14. Baldauf, K.J., et al., Oral administration of a recombinant cholera toxin B subunit promotes mucosal healing in the colon. Mucosal Immunol, 2017. 10(4): p. 887900.

15. Zhang, Y.Z. and Y.Y. Li, Inflammatory bowel disease: pathogenesis. World J Gastroenterol, 2014. 20(1): p. 91- 
16. Yadav, V., et al., Gastrointestinal stability of therapeutic anti-TNF $\alpha$ IgG1 monoclonal antibodies. Int J Pharm, 2016. 502(1-2): p. 181-7.

17. Lautenschlager, C., et al., Drug delivery strategies in the therapy of inflammatory bowel disease. Adv Drug Deliv Rev, 2014. 71: p. 58-76.

18. Gallo, G., P.G. Kotze, and A. Spinelli, Surgery in ulcerative colitis: When? How? Best Practice \& Research Clinical Gastroenterology, 2018. 32-33: p. 71-78.

19. Fell, J.M., et al., Management of ulcerative colitis. Archives of disease in childhood, 2016. 101(5): p. 469-474.

20. Danese, S., G. Fiorino, and L. Peyrin-Biroulet, Positioning Therapies in Ulcerative Colitis. Clin Gastroenterol Hepatol, 2020. 18(6): p. 1280-1290 e1.

21. Tripathi, K. and J.D. Feuerstein, New developments in ulcerative colitis: latest evidence on management, treatment, and maintenance. Drugs in context, 2019. 8: p. 212572-212572.

22. Feuerstein, J.D., A.C. Moss, and F.A. Farraye, Ulcerative Colitis. Mayo Clinic Proceedings, 2019. 94(7): p. 1357-1373.

23. Boal Carvalho, P. and J. Cotter, Mucosal Healing in Ulcerative Colitis: A Comprehensive Review. Drugs, 2017. 77(2): p. 159-173.

24. Pineton de Chambrun, G., P. Blanc, and L. Peyrin-Biroulet, Current evidence supporting mucosal healing and deep remission as important treatment goals for inflammatory bowel disease. Expert Rev Gastroenterol Hepatol, 2016. 10(8): p. 915-27.

25. Gunnarsson, C., et al., Direct health care insurer and out-of-pocket expenditures of inflammatory bowel disease: evidence from a US national survey. Dig Dis Sci, 2012. 57(12): p. 3080-91.

26. Beck, P.L., et al., Transforming growth factor-beta mediates intestinal healing and susceptibility to injury in vitro and in vivo through epithelial cells. Am J Pathol, 2003. 162(2): p. 597-608.

27. Dieleman, L.A., et al., Role of animal models for the pathogenesis and treatment of inflammatory bowel disease. Scand J Gastroenterol Suppl, 1997. 223: p. 99104.

28. Leoni, G., et al., Wound repair: role of immune-epithelial interactions. Mucosal Immunology, 2015. 8(5): p. 959-968.

29. Devlin, S.M. and R. Panaccione, Evolving inflammatory bowel disease treatment paradigms: top-down versus step-up. Med Clin North Am, 2010. 94(1): p. 1-18.

30. Royal, J.M., et al., A modified cholera toxin B subunit containing an ER retention motif enhances colon epithelial repair via an unfolded protein response. Faseb j, 2019. 33(12): p. 13527-13545.

31. Lencer, W.I., et al., Targeting of cholera toxin and Escherichia coli heat labile toxin in polarized epithelia: role of COOH-terminal KDEL. J Cell Biol, 1995. 131(4): p. 951-62.

32. Capitani, M. and M. Sallese, The KDEL receptor: new functions for an old protein. FEBS Lett, 2009. 583(23): p. 3863-71.

33. Bertolotti, A., et al., Increased sensitivity to dextran sodium sulfate colitis in IRE1beta-deficient mice. J Clin Invest, 2001. 107(5): p. 585-93. 
34. Zhang, H., et al., Colitis Is Effectively Ameliorated by ( \pm )-8-Acetonyldihydrocoptisine via the XBPl-NF- $\kappa B$ Pathway. Front Pharmacol, 2017. 8: p. 619.

35. Wang, J.M., et al., Inositol-Requiring Enzyme 1 Facilitates Diabetic Wound Healing Through Modulating MicroRNAs. Diabetes, 2017. 66(1): p. 177-192.

36. Royal, J.M., M.A. Reeves, and N. Matoba, Repeated Oral Administration of a KDEL-tagged Recombinant Cholera Toxin B Subunit Effectively Mitigates DSS Colitis Despite a Robust Immunogenic Response. Toxins (Basel), 2019. 11(12).

37. Moore, L., K. Hamorsky, and N. Matoba, Production of Recombinant Cholera Toxin B Subunit in Nicotiana benthamiana Using GENEWARE(R) Tobacco Mosaic Virus Vector. Methods Mol Biol, 2016. 1385: p. 129-37.

38. Dertzbaugh, M.T. and L.M. Cox, The affinity of cholera toxin for $\mathrm{Ni2}+\mathrm{ion}$. Protein Eng, 1998. 11(7): p. 577-81.

39. Liu, L., et al., pH-Responsive carriers for oral drug delivery: challenges and opportunities of current platforms. Drug Deliv, 2017. 24(1): p. 569-581.

40. Wolk, O., et al., New targeting strategies in drug therapy of inflammatory bowel disease: mechanistic approaches and opportunities. Expert Opin Drug Deliv, 2013. 10(9): p. 1275-86.

41. Feuerstein, J.D. and A.S. Cheifetz, Ulcerative colitis: epidemiology, diagnosis, and management. Mayo Clin Proc, 2014. 89(11): p. 1553-63.

42. Muheem, A., et al., A review on the strategies for oral delivery of proteins and peptides and their clinical perspectives. Saudi Pharmaceutical Journal, 2016. 24(4): p. 413-428.

43. Kuentz, M., R. Holm, and D.P. Elder, Methodology of oral formulation selection in the pharmaceutical industry. European Journal of Pharmaceutical Sciences, 2016. 87: p. 136-163.

44. Li, X., et al., Site-specific targeted drug delivery systems for the treatment of inflammatory bowel disease. Biomedicine \& Pharmacotherapy, 2020. 129: p. 110486.

45. Ziaee, A., et al., Spray drying of pharmaceuticals and biopharmaceuticals: Critical parameters and experimental process optimization approaches. Eur J Pharm Sci, 2019. 127: p. 300-318.

46. Kanojia, G., et al., Developments in the formulation and delivery of spray dried vaccines. Human vaccines \& immunotherapeutics, 2017. 13(10): p. 2364-2378.

47. Sollohub, K. and K. Cal, Spray drying technique: II. Current applications in pharmaceutical technology. Journal of Pharmaceutical Sciences, 2010. 99(2): p. 587-597.

48. Ameri, M. and Y.-F. Maa, Spray Drying of Biopharmaceuticals: Stability and Process Considerations. Drying Technology, 2006. 24(6): p. 763-768.

49. Snyder, H.E., Pharmaceutical spray drying: solid-dose process technology platform for the 21st century. Ther Deliv, 2012. 3(7): p. 901-12.

50. Langford, A., et al., Drying technologies for biopharmaceutical applications: Recent developments and future direction. Drying Technology, 2018. 36(6): p. 677-684.

51. Wirtz, S., et al., Chemically induced mouse models of acute and chronic intestinal inflammation. Nat Protoc, 2017. 12(7): p. 1295-1309. 
52. Kim, J.J., et al., Investigating intestinal inflammation in DSS-induced model of IBD. Journal of visualized experiments : JoVE, 2012(60): p. 3678.

53. Cooper, H.S., et al., Clinicopathologic study of dextran sulfate sodium experimental murine colitis. Lab Invest, 1993. 69(2): p. 238-49.

54. Nugent, S.G., et al., Intestinal luminal pH in inflammatory bowel disease: possible determinants and implications for therapy with aminosalicylates and other drugs. Gut, 2001. 48(4): p. 571-7.

55. Koziolek, M., et al., Investigation of $p H$ and Temperature Profiles in the GI Tract of Fasted Human Subjects Using the Intellicap $((R))$ System. J Pharm Sci, 2015. 104(9): p. 2855-63.

56. Royal, J.M. and N. Matoba, Therapeutic Potential of Cholera Toxin B Subunit for the Treatment of Inflammatory Diseases of the Mucosa. Toxins (Basel), 2017. 9(12).

57. Hetz, C., K. Zhang, and R.J. Kaufman, Mechanisms, regulation and functions of the unfolded protein response. Nature Reviews Molecular Cell Biology, 2020. 21(8): p. 421-438.

58. Wang, R., et al., Immune regulation of the unfolded protein response at the mucosal barrier in viral infection. Clinical \& translational immunology, 2018. 7(4): p. e1014-e1014.

59. Boyko, T.V., et al., Inhibition of IRE1 results in decreased scar formation. Wound repair and regeneration : official publication of the Wound Healing Society [and] the European Tissue Repair Society, 2017. 25(6): p. 964-971.

60. Ajmera, A. and R. Scherließ, Stabilisation of proteins via mixtures of amino acids during spray drying. Int J Pharm, 2014. 463(1): p. 98-107.

61. Maltesen, M.J. and M. van de Weert, Drying methods for protein pharmaceuticals. Drug Discov Today Technol, 2008. 5(2-3): p. e81-8.

62. Liao, Y.H., M.B. Brown, and G.P. Martin, Investigation of the stabilisation of freeze-dried lysozyme and the physical properties of the formulations. Eur $\mathbf{J}$ Pharm Biopharm, 2004. 58(1): p. 15-24.

63. Tian, F., S. Sane, and J.H. Rytting, Calorimetric investigation of protein/amino acid interactions in the solid state. Int J Pharm, 2006. 310(1-2): p. 175-86.

64. Pastor, M., et al., Cellulose acetate phthalate microparticles containing Vibrio cholerae: steps toward an oral cholera vaccine. J Drug Target, 2014. 22(6): p. 478-87.

65. Goins, B. and E. Freire, Thermal stability and intersubunit interactions of cholera toxin in solution and in association with its cell-surface receptor ganglioside GM1. Biochemistry, 1988. 27(6): p. 2046-52.

66. Surewicz, W.K., J.J. Leddy, and H.H. Mantsch, Structure, stability, and receptor interaction of cholera toxin as studied by Fourier-transform infrared spectroscopy. Biochemistry, 1990. 29(35): p. 8106-11.

67. Ohrem, H.L., et al., Why is mannitol becoming more and more popular as a pharmaceutical excipient in solid dosage forms? Pharmaceutical development and technology, 2014. 19(3): p. 257-62.

68. Naini, V. Physical and Chemical Stability of Spray Dried Sugars and ProteinSugar MolecuIar Mixtures for Inhalation. 1996. 
69. Rowe, R.C., P. Sheskey, and M. Quinn, Handbook of pharmaceutical excipients. 2009: Libros Digitales-Pharmaceutical Press.

70. Maury, M., et al., Effects of process variables on the powder yield of spray-dried trehalose on a laboratory spray-dryer. European Journal of Pharmaceutics and Biopharmaceutics, 2005. 59(3): p. 565-573.

71. Jain, M., et al., Spray Drying in Pharmaceutical Industry: A Review. 2012. 4: p. 74-79. 


\section{CURRICULUM VITA}

NAME:

ADDRESS:

DOB:

EDUCATION

\& TRAINING:

AWARDS:

PUBLICATIONS:

NATIONAL POSTER PRESENTATIONS:
Micaela Ann Reeves

Department of Pharmacology and Toxicology

505 South Hancock Street Lab 424F

Louisville, Kentucky 40202

June 19, 1996

B.A. Biochemistry

Hanover College

2014-2018

Katherine Parker Academic Merit Scholarship Award, 2014

B.A. awarded Cum Laude, 2018

Royal, J. M., et al. (2019). Repeated Oral Administration of a KDEL-tagged Recombinant Cholera Toxin B Subunit Effectively Mitigates DSS Colitis Despite a Robust Immunogenic Response. Toxins, 11(12), 678.

Morris, D. A., et al. (2021). Isolation and detection of a KDEL-tagged recombinant cholera toxin b subunit from nicotiana benthamiana. Process Biochemistry (Barking, London, England), 101, 42-49.

"Toxicological findings of a recombinant cholera toxin B subunit variant with therapeutic potential in ulcerative colitis." - Poster given at Crohn's and Colitis Congress (January 2021) 